\title{
A Scientometric Approach to Analyze Scientific Development on Renewable Energy Sources
}

\author{
Jones Luís Schaefer ${ }^{1 \dagger}$, Julio Cezar Mairesse Siluk ${ }^{1}$, \\ Ismael Cristofer Baierle ${ }^{1}$, Elpidio Oscar Benitez Nara ${ }^{2}$
}

Citation: Schaefer, J.L., Siluk, J.C.M., Baierle,

${ }^{1}$ Universidade Federal de Santa Maria, Avenida Roraima, 1000, Santa Maria 97105-900, Brazil ${ }^{2}$ Universidade de Santa Cruz do Sul, Avenida Independência, 2293, Santa Cruz, RS 96815-900, Brazil

\begin{abstract}
Purpose: This paper aims to point out the scientific development and research density of renewable energy sources such as photovoltaic, wind, and biomass, using a mix of computational tools. Based on this, it was possible to verify the existence of new research trends and opportunities in a macro view regarding management, performance evaluation, and decision-making in renewable energy generation systems and installations.
\end{abstract}

I.C., \& Nara, E.O.B.

(2021). A Scientometric approach to analyze scientific development on renewable energy sources. Journal of Data and Information Science, 6(1), 87-119. https://doi. org/10.2478/jdis-20210009

Received: Apr. 22, 2020 Revised: Jun. 13, 2020;

Aug. 22, 2020

Accepted: Sep. 10, 2020

Design/methodology/approach: A scientometric approach was used based on a research protocol to retrieve papers from the Scopus database, and through four scientometric questions, to analyze each area. Software such as the Science Mapping Analysis Software Tool (SciMAT) and Sci2 Tool were used to map the science development and density.

Findings: The scientific development of renewable energy areas is highlighted, pointing out research opportunities regarding management, studies on costs and investments, systemic diagnosis, and performance evaluation for decision-making in businesses in these areas.

Research limitations: This paper was limited to the articles indexed in the Scopus database and by the questions used to analyze the scientific development of renewable energy areas.

Practical implications: The results show the need for a managerial perspective in businesses related to renewable energy sources at the managerial, technical, and operational levels, including performance evaluation, assertive decision making, and adequate use of technical and financial resources.

Originality/value: This paper shows that there is a research field to be explored, with gaps to fill and further research to be carried out in this area. Besides, this paper can serve as a basis for other studies and research in other areas and domains.

Keywords Solar energy; Photovoltaic energy; Wind energy; Biomass energy; Scientometrics

\footnotetext{
† Corresponding author: Jones Luís Schaefer (E-mail: engjlschaefer@yahoo.com.br).
}

Information Science

http://www.jdis.org https://www.degruyter.com/view/j/jdis 


\section{Research Paper}

\section{Introduction}

Sustainable energy generation holds great promise for resolving current energy and environmental challenges (Hu et al., 2017) together with strategies for managing limited energy resources (Schaefer et al., 2020). The main goal of increasing the spread and use of renewable energy generation systems is to reduce the use of fossil fuels and greenhouse gas emissions (Roselli et al., 2019). The transition to sustainable energy can be achieved in many ways (Longo, Foiadelli, \& Yaïci, 2019) and renewable energy structures must be managed with care so that they do not harm the environment (Ben Jebli, Ben Youssef, \& Apergis, 2019). Growing concern about the effects of energy production and the use of fossil fuels on global warming also generates investment opportunities in energy efficiency and renewable energy projects (Martí-Ballester, 2019). Photovoltaic (PV) and wind energy sources are the most widespread since their maturity allows generation with a high degree of efficiency (Lopez-Rey et al., 2019), but biomass can also be considered as an efficient renewable energy generation system (Ducom et al., 2020).

These three sources of renewable energy generation account for just over $60 \%$ of the total jobs generated in renewable energy generation plants (IRENA, 2018). Solar energy has been the subject of extensive studies and received numerous applications around the world for the production of electricity in residential and commercial sectors (Chel \& Kaushik, 2018). It has a characteristic that favors its massive penetration in the urban environment because solar radiation is received everywhere with levels of intensity that allow the production of electricity (Lopez-Rey et al., 2019), being determinant for this market advance (Rosa et al., 2018). Wind energy is clean, abundant, inexhaustible, and environmentally preferable (Oyedepo, Adaramola, \& Paul, 2012) and refers to the development of wind farms near beaches, rivers, or lakes to produce electricity from the wind (Tarfaoui, Nachtane, $\&$ Boudounit, 2019). Finally, biomass energy is clean and renewable energy and is also considered an alternative to fossil fuels (Liu, Feng, \& He, 2019), as it can contribute significantly to reduce the environmental impacts associated with using waste from other processes for generation, such as the use of residues from olive oil production (Ducom et al., 2020).

As introduced above, this article focuses on these three types of sustainable energy generation, seeking to show the basic concepts and to show if there is something in common between these different areas of research and the advances obtained, identifying the potential industry-university-research collaboration (Xu et al., 2020). In this sense, due to the increase in energy demand, researchers are

Journal of Data and looking for reliable and efficient techniques and applications related to management, through which the most appropriate type of energy source is chosen, considering 
different criteria (Chen et al., 2017). Therefore, it is interesting to assess in which areas further progress can be made, where studies are still few, and how this can assist in the development and management of these technologies. This is important because the dissemination, knowledge, and control of these renewable energy sources will lead to a better level of growth, reducing environmental risks and consequently improving the social, financial and economic well-being of the world (Haseeb et al., 2019). Taking these aspects into a broad approach, the purpose of this paper is to determine the scientific development and research density in the areas that make up the main renewable energies: wind energy, photovoltaic energy and biomass energy, and, from this, to verify the existence of new research trends and opportunities in a macro view, regarding management, performance evaluation and decision-making in renewable energy generation systems and installations.

To achieve this purpose, a scientometric analysis of publications on renewable energy sources was done. Scientometrics is the science of measuring and analyzing quantitatively the advancement of science (Abramo, 2018; Sassmannshausen \& Volkmann, 2018), and is used to evaluate the performance of research and science areas, and to identify research gaps and trends (Kumar \& Kaliyaperumal, 2015). This analysis uses methods for science mapping to transform data, networks, and maps into useful knowledge (Cobo et al., 2011b). These science mapping methods can involve temporal or longitudinal analysis (de Solla Price \& Gürsey, 1975; Garfield, 1994), network analysis (Carrington, Scott, \& Wasserman, 2005; Cook \& Holder, 2006; Newman, 2001a, 2001b; Skillicorn, 2007; Wasserman \& Faust, 1994; $\mathrm{Wu}, 2019$ ), performance analysis (Cobo et al., 2011b), or geospatial analysis (Batty, 2003; Leydesdorff \& Persson, 2010; Small \& Garfield, 1985; Wuestman, Hoekman, \& Frenken, 2019). Light, Polley, and Börner (2014) proposed organizing these methods into four questions:

- "When?": these are temporal studies that make analyses in chronological order;

- "Who?": this type of study analyzes the information obtained through a map of networks elaborated with algorithms and techniques of information science;

- "What?": language analysis elucidates this question to answer what is being researched;

- "Where?": geospatial studies based on cartographic analyses.

These four questions were used to analyze the research on renewable energy sources, providing convincing analysis of the extent of the studies (Garner et al., 2020) and guiding new non-repetitive studies. To accomplish this approach, computational tools such as Sci2 Tool and SciMAT were used to answer each scientometric question.

Journal of Data and Information Science

http://www.jdis.org https://www.degruyter.com/view/j/jdis 


\section{Research Paper}

The use of this software, as well as the methodological procedures, are presented in Section 2, while in Section 3 the scientific mapping will be shown and discussed, and Section 4 comprises the concluding thoughts.

\section{Materials and methods}

The methodological procedures followed in this paper can be organized in four stages, which are detailed in the sequence:

\subsection{Stage 1 - Research scope}

In the first stage, the research scope was defined as being three areas from renewable energy sources: photovoltaic energy, wind energy, and biomass energy. These three areas were chosen because they account for over $60 \%$ of the total jobs generated in renewable energy generation plants (IRENA, 2018). Considering these three areas, the research was structured to respond adequately to the suggested questions and enabled the measurement of research density, pointing out the scientific development of each one of those three renewable energy sources.

\subsection{Stage 2 - Search filters definition}

At this stage, the search filters were defined to enable a search for articles with a potential possibility to respond to the objective of the article. Considering that the objective of this article is to research the development and the density of the research that involves the three types of generation, the search terms were defined as solar or photovoltaic energy, wind energy, and biomass energy. However, after initial tests on the database, it was found that using the terms referring to the three energy sources, the scope of the themes studied is wide, making it difficult to disclose research related to management, performance evaluation, and decision making related to these energy sources. This way, the search term "renewable energy" was added with the Boolean operator AND to refine the searches and to enable the recovery and inclusion of a greater number of articles with an approach aimed at the management of those energy sources considering them as renewable energy sources. Research areas in the Scopus database were limited to "Energy; Engineering; Decision Sciences; Business, Management and Accounting; Economics Econometrics and Finance", since a relationship can be established between the technologies used to generate energy through renewable sources and business management through performance evaluation, cost and investment management, business diagnosis and decision making. The first papers published in these areas were from the 1970s, but the period considered was the last 15 years, where a

Journal of Data and considerable increase in publications occurred only in 2008 and 2009 (see Figure 2 in Section 3.1) with the approval by the European Parlament on April 23, 2009, of 
the Directive 2019/28/CE (Parlamento Europeu, 2009). So, starting the analysis from 2005 onwards, it was possible to study the themes considering this visible increase in the publications. Those search filters are presented in Table 1.

Table 1. Search filters.

\begin{tabular}{|c|c|c|c|}
\hline Filter & Wind energy & Photovoltaic energy & Biomass energy \\
\hline Document type & Articles & Articles & Articles \\
\hline Search in & Title, abstract or keywords & Title, abstract or keywords & Title, abstract or Keywords \\
\hline \multirow[t]{5}{*}{ Subject área } & Energy; Engineering; & Energy; Engineering; & Energy; Engineering; \\
\hline & Decision Sciences; Business, & Decision Sciences; Business, & Decision Sciences; Business, \\
\hline & Management and Accounting; & Management and Accounting; & Management and \\
\hline & Economics, & Economics, & Accounting; Economics, \\
\hline & Econometrics and Finance & Econometrics and Finance & Econometrics and Finance \\
\hline Years & 2005-2019 & 2005-2019 & 2005-2019 \\
\hline \multirow[t]{2}{*}{ Search terms } & "wind energy" AND & "solar energy" OR & "biomass energy" AND \\
\hline & "renewable energy & $\begin{array}{l}\text { "photovoltaic energy" AND } \\
\text { "renewable energy" }\end{array}$ & "renewable energy \\
\hline
\end{tabular}

\subsection{Stage 3 - To retrieve articles}

In Stage 3 the search in the Scopus database was done, and with the search filters detailed in Table 1, the number of retrieved articles was:

- Wind energy: 3,121 articles;

- Photovoltaic energy: 4,744 articles;

- Biomass energy: 332 articles.

\subsection{Stage 4-Analysis}

Based on the retrieved articles from Stage 3, Stage 4 was divided into four analyses based on the four questions proposed by Light, Polley, and Börner (2014). To answer these questions it was proposed to use a science mapping analysis developed through the following tasks (Börner, Chen, \& Boyack, 2005; Cobo et al., 2011b, 2012):

- Preprocessing: data cleaning to eliminate errors and duplicated information such as duplicate articles, names, and other information. This task can occur either directly in the database or in the software used for analysis;

- Network extraction: relations between two units, such as words or authors, are established;

- Normalization: use of data normalization procedures, as an equivalence index, to enable reliable data analysis (Baierle et al., 2020);

- Mapping: application of techniques to build the sciences maps and graphics;

- Analysis: discovering useful knowledge from data, networks, and maps (Cobo et al., 2011b), such as node degrees, edges heights, or other measures;

- Visualization: representation techniques to show a science map enabling analysis.

Journal of Data and Information Science

http://www.jdis.org https://www.degruyter.com/view/j/jdis 


\section{Research Paper}

These tasks were performed for the development of the analyzes presented in Section 3.

\subsubsection{Computational tools used}

Microsoft Excel software was used to perform graphics to allow temporal and geographic analysis. Another tool used to answer the research questions was SciMAT, which is a freeware software used for mapping the science, allowing researchers to analyze the intellectual, social and conceptual evolution of a specific scientific field (Cobo et al., 2011a). SciMAT is composed of three modules to develop a science mapping approach: the first to manage entities knowledge, the second to carry out the science mapping analysis, and the third to generate results and maps (Martínez et al., 2015). After importing data in ISI, RIS, or csv format, the SciMAT workflow can be divided into four stages (Cobo et al., 2012; Cobo et al., 2015):

a) Build the data set: configuration of the periods, the aspects to analyze, and the data to be used;

b) Create and normalize the network: the network is built using co-occurrence or coupling relations, filtering to show only representative items;

c) Apply a clustering algorithm to get the map: selection of the clustering algorithm to be used;

d) Perform a set of analyses: the configuration and execution of the analyses.

Four types of maps that SciMAT generates were used in this research: overlapping maps (presented in Figure 2), evolution maps (presented in Figures 6, 7, and 8), cluster's network and strategic diagrams (presented in Figure 9) (Kipper et al., 2020). With these maps, it is possible to highlight some starting points for other research, such as through the evolution maps, where the researcher can search for a trend based on connections not yet consolidated on the map, or even search for the co-occurrence of words that cannot be explained intuitively. Through the clustering algorithms it is possible to identify groups and subgroups in a research area according to the selected similarity criteria (da Costa et al., 2019). In this paper, the SciMAT period was subdivided into five periods of three years each, providing a punctual analysis of the evolution of the words used and clarifying the evolutionary characteristics of the research.

To research between authors and answer the "Who" question, the Sci2 Tool was used. The Sci2 Tool is a set of computational tools designed to study science (Guler et al., 2016) through network analysis, providing a visualization of datasets at the micro, meso, and macro levels (Light, Polley, \& Börner, 2014; Sci2 Tool, 2019). The first analyses involving networks were the studies of citations networks Information Science (Newman, 2001a, 2001b), later being developed as maps of authors that help to 
identify who contributed to the science, homogeneity vs. heterogeneity, cause and effect, speed of science, monitoring and evaluating the evolution of areas for further scientific research (Börner et al., 2012). Author networks are important but do not alone provide enough information to conclude whether an author is relevant in his or her research area (Nara et al., 2019). In the authors' networks of this article, the names of the authors who centralize the largest research groups in each theme are highlighted, but it should be noted that although smaller, the other networks also have scientific relevance in the topics addressed. In this research, author networks are aggregated with other analyses to obtain a comprehensive understanding of renewable energy research areas.

\section{Results and discussion}

In the following, the results obtained from the analysis carried out with the computational tools are presented.

\subsection{Temporal analysis}

The first question answered, "When?", brought a temporal analysis, as already mentioned in Section 2.2, where the period considered in the searches was the last 15 years, and this choice is justified by the graph shown in Figure 1.

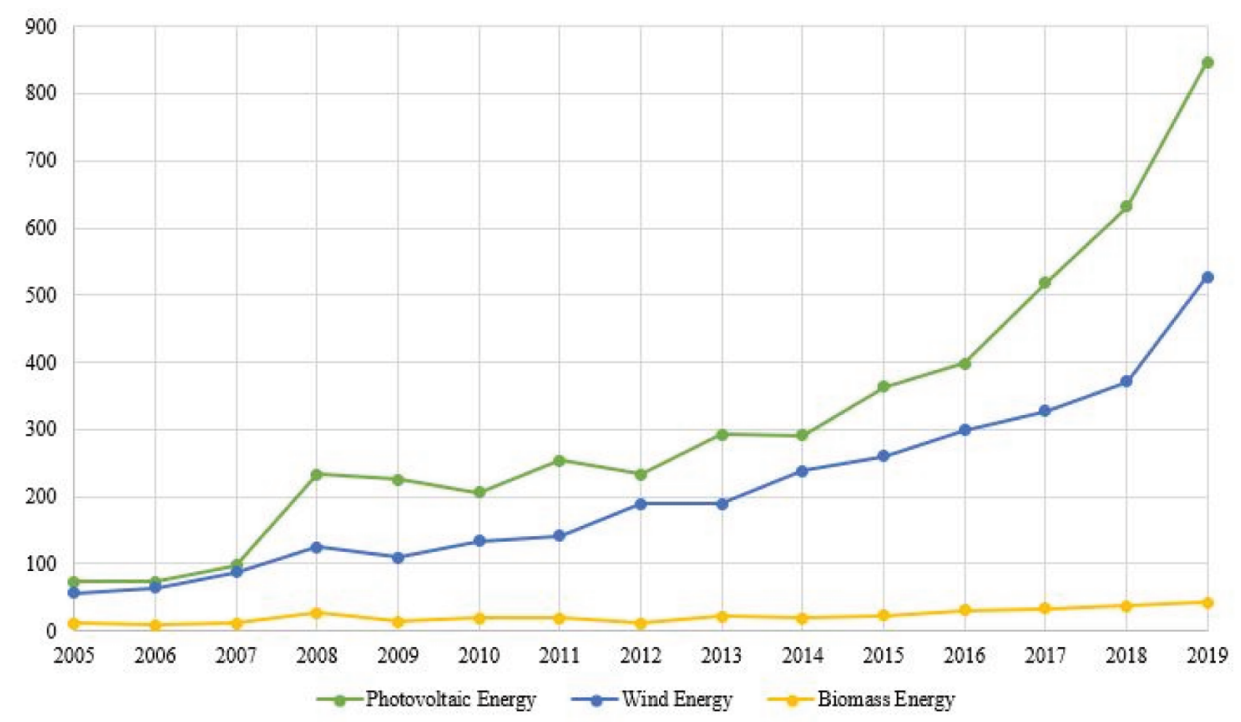

Figure 1. Quantitative temporal analysis.

Figure 2 presents an overlapping map elaborated through SciMAT and adapted to show all pertinent information. This graphic shows the behavior of the number

Journal of Data and Information Science

http://www.jdis.org https://www.degruyter.com/view/j/jdis 


\section{Research Paper}

of words related to the three renewable energy sources in each of the following periods: 2005-2007, 2008-2010, 2011-2013, 2014-2016, and 2017-2019. The time was divided in this way to allow an evaluation of the characteristics of the words used.

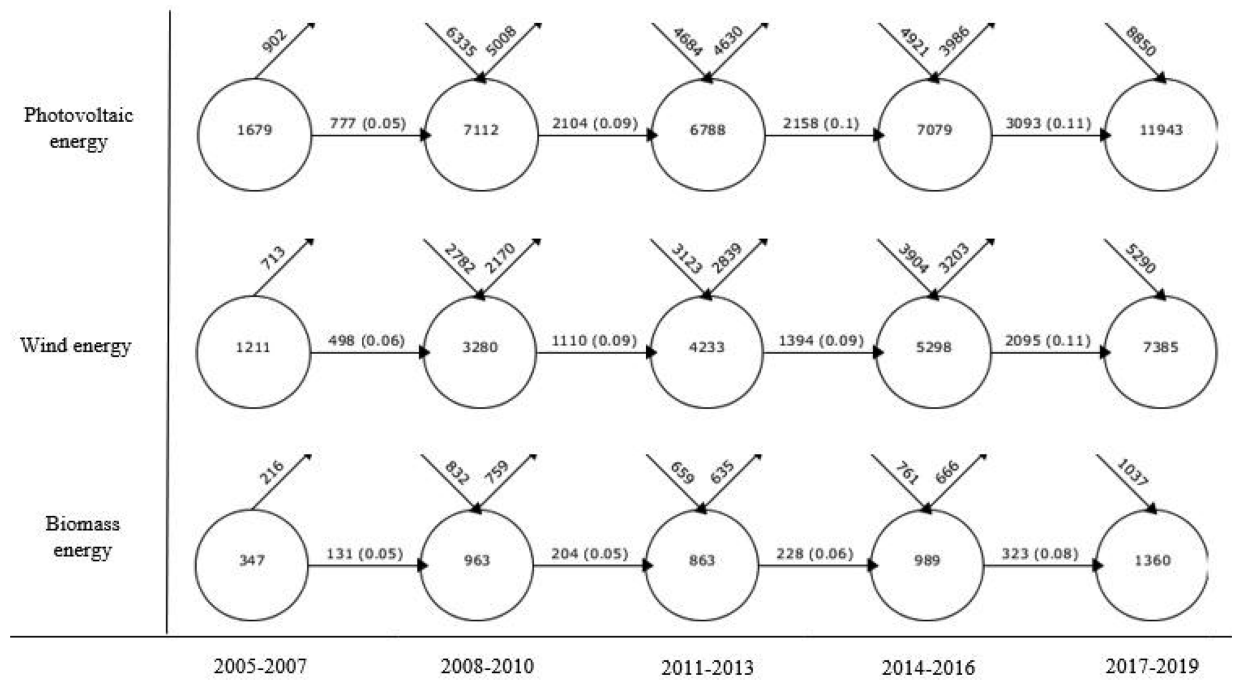

Figure 2. Overlapping map with the number of related words per period.

From Figure 1, it is clear that photovoltaic energy has the largest number of articles and words, followed by wind energy, and - with a much smaller numberbiomass energy. Figure 2 shows the number of words related to each renewable energy source per period. To obtain this comparative analysis of words by period, the metadata of the retrieved articles, excluding the references, were exported from the Scopus database in the ".ris" format and imported into SciMAT. Thus, for each type of renewable energy source researched, an analysis was carried out. Photovoltaic energy has 1,679 words in the first period, rising to 11,943 in the last period, while wind energy has 1,211 in the first period and 7,385 in the last period, and biomass energy has 347 in the first period and 1,360 in the last period. From the arrows directed to the clusters, one also perceives a great aggregation of new words into the research, as well as an exit of words of the searches from the arrows that have the direction exiting the clusters. It is noteworthy that the number of words related to research in photovoltaic energy remained nearly stable in periods two, three, and four, increasing considerably in the last period, while for wind energy research, the number of words increased gradually, and in biomass energy, the number of words

Journal of Data and in the second, third, and fourth periods remained nearly stable, only increasing in Information Science the last period. 
This difference in the number of studies may be due to the difference between the systems, especially concerning the region of installation, ease, and minimum requirements. For photovoltaic energy, the direction in which the panels are installed will not prevent the system from generating energy, but will only reduce its efficiency (Daghigh et al., 2011). Solar energy is the most abundant energy on earth, and photovoltaic systems do not need a sunny day to operate, because even on cloudy days they produce electricity, but at a lower intensity than on clear days (Hassan et al., 2020). Many studies have been carried out to develop different materials for the construction of panels, generating less waste and also not allowing the system to overheat (Letcher, 2018; Salameh, New York, \& Diego, 2014). From the irradiation incident on the photovoltaic module, only 15 to $20 \%$ is converted into electrical energy, hence the great efforts and studies to improve the performance (Fayaz et al., 2019). For wind power to be considered technically feasible, a minimum wind velocity of 7 to $8 \mathrm{~m} / \mathrm{s}$ is required (Poole et al., 1993). Therefore, wind energy is only economically viable in places where wind conditions are good for wind turbines, making the system still unstable and less attractive than photovoltaic (Ayyarao, 2019). The concept of biomass comprises all organic matter used as energy sources, such as agricultural waste, wood, and plants. Biomass processing is very difficult due to the low calorific value, low bulk density, and high moisture content of raw materials, which seriously limits its use on a large scale (Stolarski et al., 2013; Suarez \& Luengo, 2003). These facts may have been decisive, such that studies in this area have not progressed over the years.

\subsection{Analysis of author networks}

In this subsection, author network maps are presented to answer the question "Who" about the terms related to renewable energy sources. In each map of authors' networks, a threshold was established, mentioned in the description of the figures, related to the size of the node so that the names of the authors with the greatest influence on the researched topics could appear. The first network is shown in Figure 3 and presents the author network for researchers who have more than five articles indexed in the Scopus database with the search terms "renewable energy" and "solar energy" or "photovoltaic energy", considering also the search filters presented in Table 1. The names of the authors who appear are those with a node degree equal to or higher than 18 .

There are nine networks with 17 authors with a node size equal to or greater than 18, and in a single network, there are eight authors in smaller interconnected networks with a node size equal to or greater than 18. Completing the map, another 15 smaller networks can still be viewed. Of those 17 authors, only seven authors have a node size equal to or greater than 25: Cabeza has node size 38, Hodge and

Journal of Data and Information Science

http://www.jdis.org https://www.degruyter:com/view/j/jdis 


\section{Research Paper}

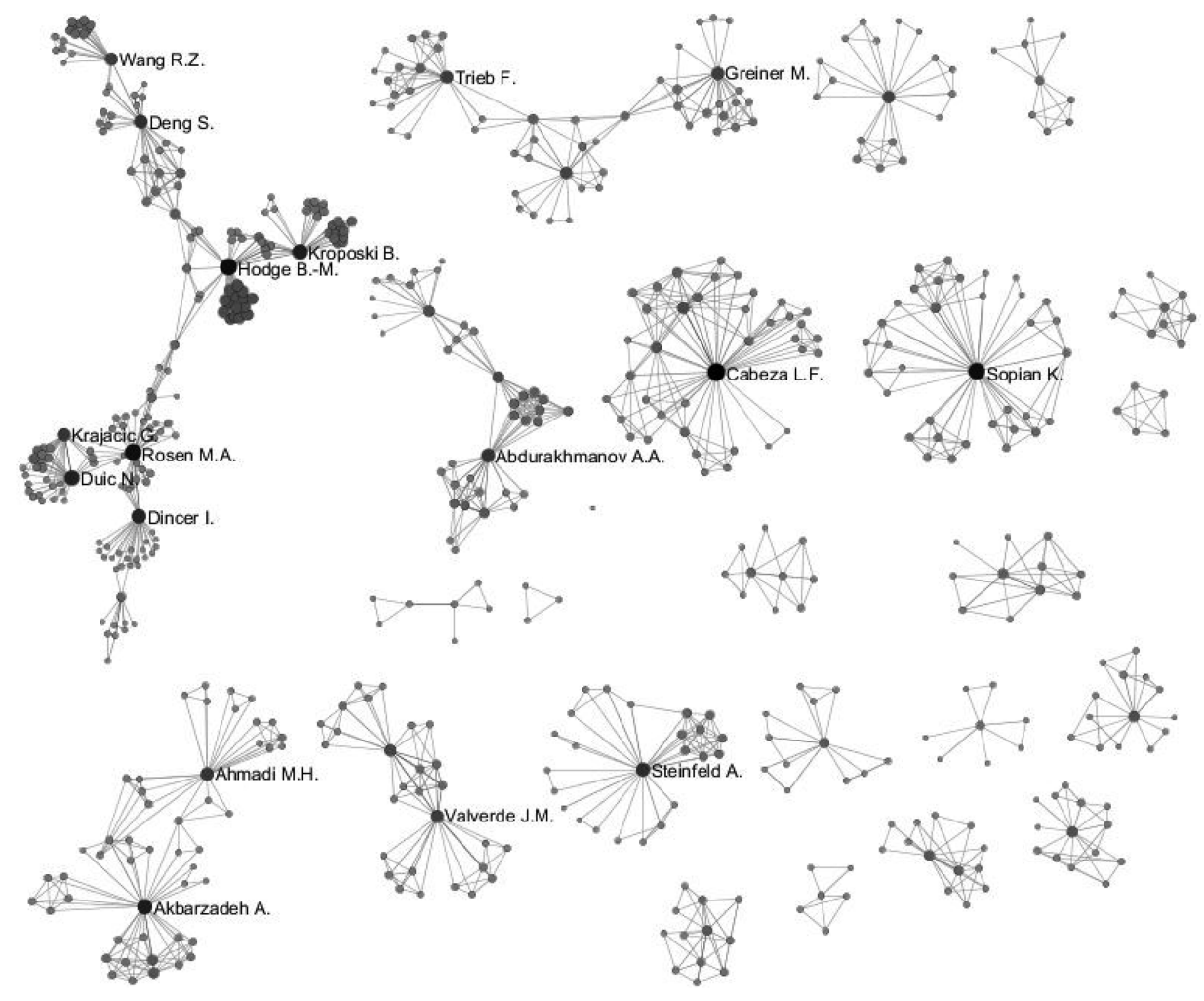

Figure 3. Authors' networks for photovoltaic energy.

Sopian have node size 34, Rosen has node size 33, Akbarzadeh and Kroposki have node size 28 and Duic has node size equal to 27.

The authors Cabeza with node degree 38 and Hodge with node degree 34 are the highest in this map. Cabeza has 12 articles related to the subject of solar or photovoltaic energy, some of them being about thermal energy storage systems (Cabeza et al., 2017; Gibb et al., 2018; Jacob et al., 2016; Peiró et al., 2018; RuizCabañas et al., 2017), key performance indicators for energy storage systems (Cabeza et al., 2015), and other correlated subjects. Hodge has seven papers indexed in Scopus about high renewable power systems (Du et al., 2018; Du et al., 2019), trends in wind and solar energy forecasting technologies (Hodge et al., 2018; Orwig et al., 2015), estimation of solar irradiance (Zhang et al., 2019), and other related articles. Sopian has 11 papers indexed in Scopus about photovoltaic thermal systems technologies (Nazri et al., 2018; Othman et al., 2013; Rukman et al., 2019), feed-in tariff policy (Bakhtyar et al., 2013; Bakhtyar et al., 2015), solar radiation prediction Information Science (Azhari et al., 2008), and other research on correlated themes. Rosen is a researcher 
with 16 papers on the subjects of exergetic analysis and assessment of different systems (Granovskii, Dincer, \& Rosen, 2007; Hacatoglu, Dincer, \& Rosen, 2011; Khalid, Dincer, \& Rosen, 2015; Rezaie, Reddy, \& Rosen, 2018), hybrid renewable energy systems for different applications (Krajačić et al., 2018; Maleki, Rosen, \& Pourfayaz, 2017; Soltani et al., 2014; Zhang et al., 2018), and others researches on similar subjects. Akbarzadeh has 10 papers on the subject, almost all about salinitygradient solar ponds related to electric power generation (Akbarzadeh, Johnson, \& Singh, 2009; Alcaraz et al., 2018; Bernad et al., 2013; Leblanc, Andrews, \& Akbarzadeh, 2010; Singh et al., 2017; Singh, Tundee, \& Akbarzadeh, 2011; Valderrama et al., 2011). Kroposki and his network are linked with the network of Hodge. They have some papers in common such as those about high renewable energy penetrated power systems (Du et al., 2018; Du et al., 2019). The last author with a node degree higher than 25 is Duic with node degree 27. Duic published papers about the integration of solar energy in the energy mix, analyzing the economic and environmental implications (Pfeifer et al., 2019), energy scenarios in Malta (Busuttil, Krajačić, \& Duić, 2008) and southeast Europe (Dominković et al., 2016), and other related papers. Among the smaller networks, the networks centralized by Patt, who has four articles on the topic, and the one centralized by Escobar, who has six articles on the subject can be mentioned. The network centralized by Patt researched on risks involving renewable energy projects (Komendantova et al., 2012), barriers for the expansion of electricity grids (Battaglini et al., 2012), and other related papers, while the network centralized by Escobar researched about the influence of solar energy resource assessment uncertainty in the levelized electricity cost of concentrated solar power plants (Hanel \& Escobar, 2013), the impact of concentrated solar power in electric power systems (Mena et al., 2019), and other related papers. When analyzing the publications from the main and some minor research networks on the subject of photovoltaic energy, it can be said that some specific studies are dealing with aspects of management and performance evaluation of this energy source, but no articles were found related to the elaboration of modeling for decision-making in these major research networks.

The next map of author networks, presented in Figure 4, is about wind energy. The author names shown are those with a node degree equal to or higher than 17 .

There are seven author networks on the subject of wind energy with at least one author with a node greater than or equal to 17 , and six authors have a node greater than or equal to 23 , indicating them as the most relevant in research related to renewable energy coming from wind: Catalão with node degree 28, Breyer and Arroyo with node degree 26, Mañana with node degree 24, Senjyu and Wang with node degree 23. Completing the map, another 23 complementary networks can still be viewed.

Journal of Data and Information Science

http://www.jdis.org https://www.degruyter:com/view/j/jdis 


\section{Research Paper}
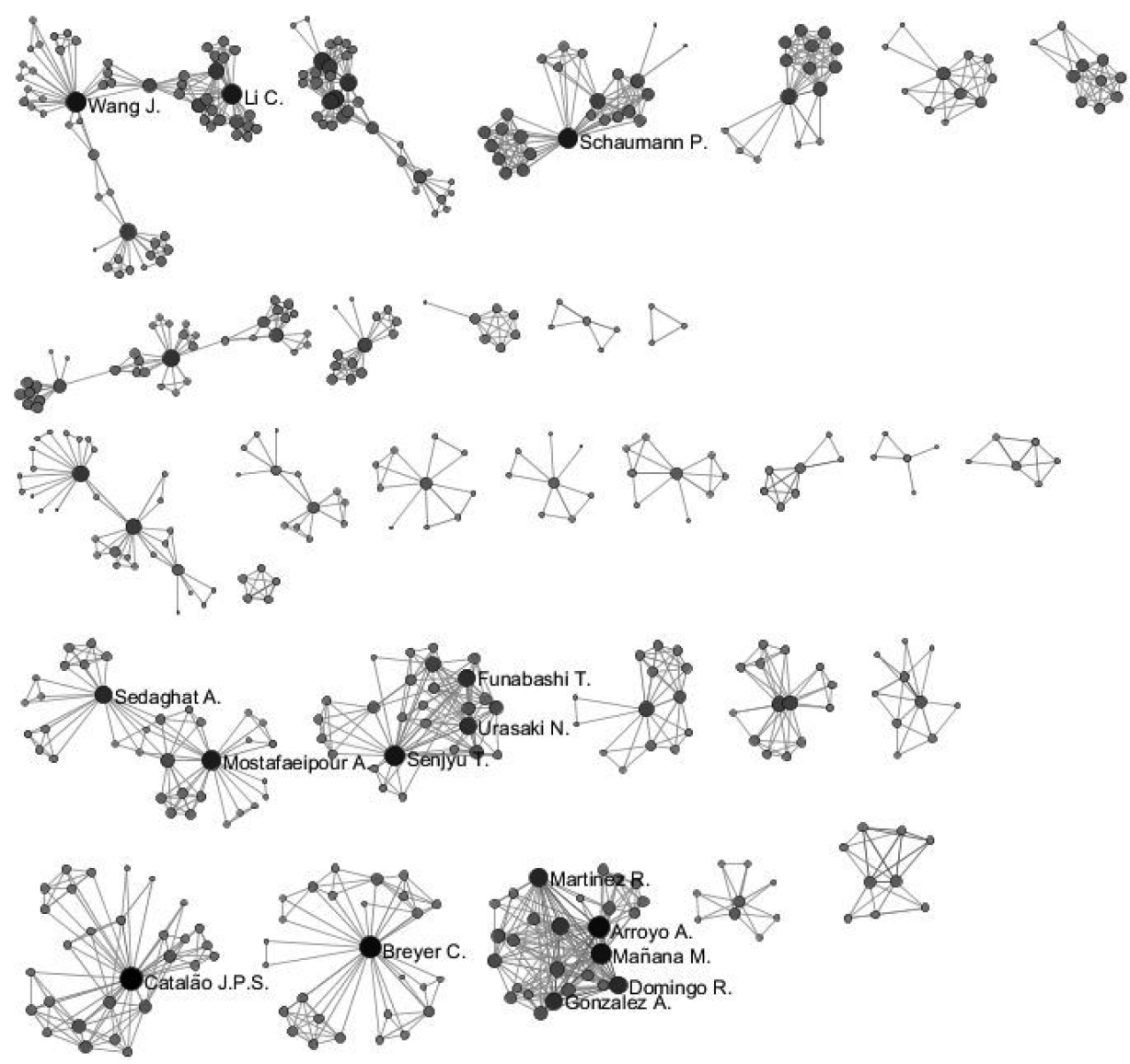

【Lเ田

Figure 4. Authors' networks for wind energy.

Catalão is a researcher with 12 papers, and he leads a network in research such as Monte Carlo simulation for optimal operation in electrical systems with high renewable sources integration (Osório et al., 2015), storage of wind energy surplus (Rodrigues et al., 2015), integration of wind energy with other renewable energy sources through a model using a stochastic heuristic Multi-Objective Multi-Criteria Decision Making method (Hajibandeh et al., 2018), and other papers on related subjects. Breyer is a researcher who has published 10 papers on the subject of wind energy as scenarios for sustainable energy in Scotland (Child et al., 2019), the Aland Islands (Child, Nordling, \& Breyer, 2017), and the Berlin-Brandenburg region, Germany, using a cost optimization approach (Moeller et al., 2014) and others.

Journal of Data and Arroyo has 10 papers on the subject and Mañana has nine papers on the subject, Information Science and they are the centralized nodes from a network. These authors study together the 
subject of $\mathrm{CO}_{2}$ footprint reduction and efficiency increase using a dynamic rating of the electricity grid (Arroyo et al., 2018), the increase of grid integration of wind energy using ampacity techniques (Madrazo et al., 2013), and the analysis of the ampacity management in a $132 \mathrm{kV}$ overhead line placed in a high-wind generation area (Madrazo et al., 2015), and other related papers. Senjyu is at the center of his network and has eight papers on the subject, including research to present an output power leveling control strategy for wind farms (Sakamoto et al., 2008; Senjyu et al., 2006), to propose a methodology for solving the generation planning problem for thermal units with wind and solar energy systems (Chakraborty et al., 2009), and other related papers. Wang has seven papers and is the center of his author network, with papers related to wind speed forecasting using several methods such as a back propagation Neural Network (Ren et al., 2014), Extreme Learning Machine, Ljung Box Q-test, and Seasonal Auto-Regressive Integrated Moving Average (Wang et al., 2015), multi-objective optimization (Yang et al., 2019), and other papers with hybrid proposals. Among the 23 complementary networks, it can be mentioned the networks centralized by Ilinca, with node degree 13, has five articles on the subject, and Fagiano, with node degree 9, has articles on the subject. The network centralized by Ilinca proposed a computer model for financial, environmental and risk analysis of a hybrid wind-diesel system with compressed air energy storage (Benchaabane et al., 2019), measured robustness as a tool to address strategic wind farm issues through multicriteria decision-making methods (Vazquez, Waaub, \& Ilinca, 2013), among other research. The network centralized by Fagiano research on themes such as the problem of launching a tethered rigid aircraft for airborne wind energy generation (Fagiano \& Schnez, 2017), the high-altitude wind power generation (Fagiano, Milanese, \& Piga, 2010), and other related research. Among the main and in the complementary author networks, there is a trend of research aimed at technologies related to the production of wind energy, the materials used, wind speed forecasting, prediction of energy scenarios in different locations, or aspects related to the deployment and production cost of this energy. From this analysis, it can be said that only one of the main research networks in this theme has articles published with some relation to the management of wind energy installations.

Figure 5 presents the author network map for biomass energy as a renewable energy source, and the names that appear are authors with node degrees equal to or higher than 8 .

From the elaborated map, we can see that few research networks operate in the area of biomass energy as a source of renewable electricity generation. There are three networks where there is at least one author with a node equal to or greater

Journal of Data and Information Science

http://www.jdis.org https://www.degruyter:com/view/j/jdis 


\section{Research Paper}
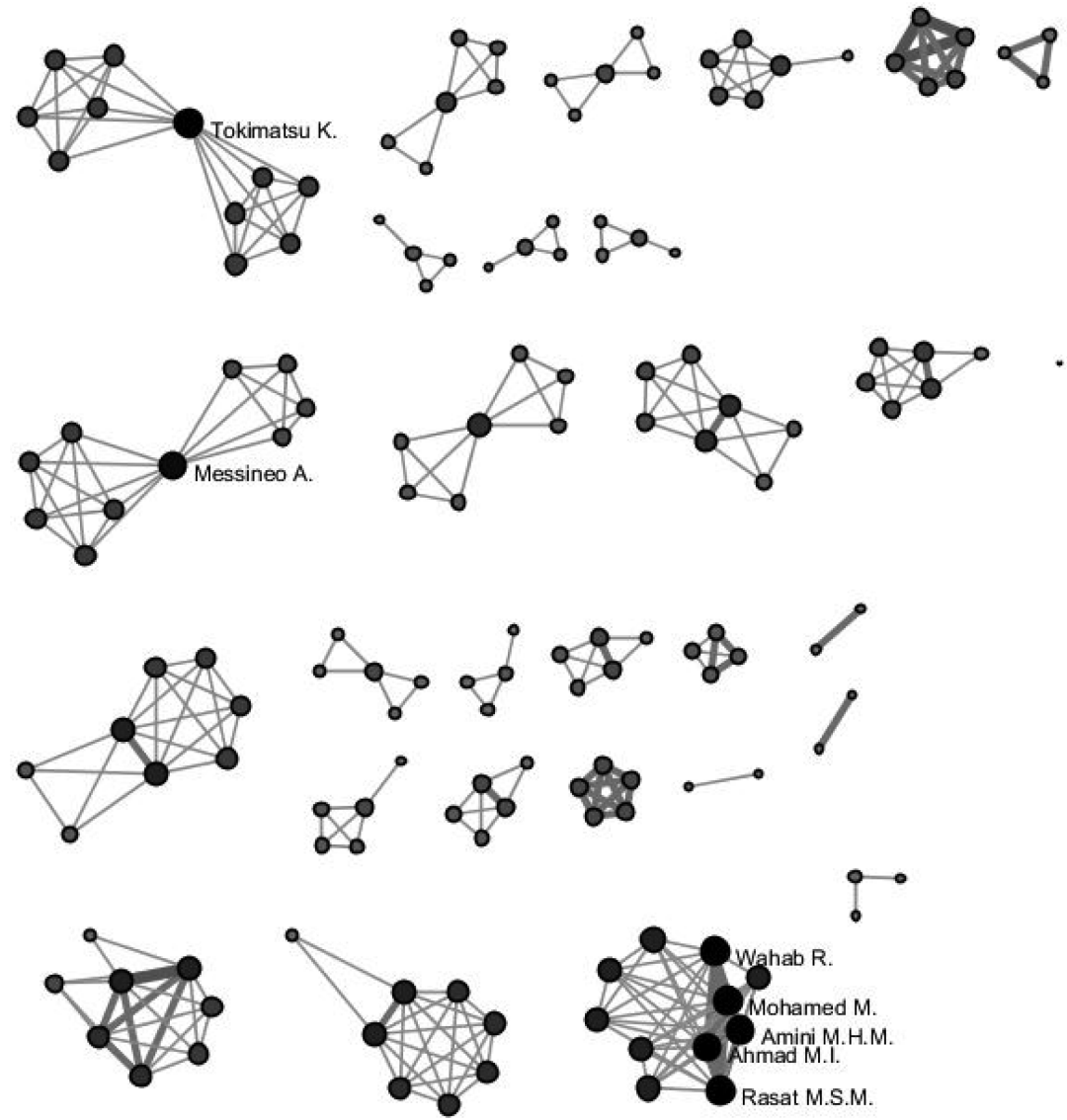

Figure 5. Authors' networks for biomass energy.

than 8 , and only two have authors with a node greater than or equal to 10 : these authors are Tokimatsu with node size 10, and the authors of the same network Wahab, Mohamed, Rasat, Amini, and Ahmad, all with node equal to 10. Completing the map, another 25 complementary networks can still be viewed.

Tokimatsu has two papers on the subject that investigate people's understanding of biomass energy (Biddinika et al., 2017), and global zero-emissions scenarios (Tokimatsu et al., 2016). The other five authors in the same network, Wahab, Mohamed, Rasat, Amini, and Ahmad, published two papers together, one about palm oil (Sharizal Sirrajudin et al., 2016), and the one about wild Leucaena Leucocephala species (Rasat et al., 2016) as a biomass energy source. Among the researches carried out by the other networks of authors, those of the network of

Journal of Data and Shahbaz which researched about the environmental Kuznets curve for $\mathrm{CO}_{2}$ emissions Information Science in 11 countries (Sinha, Shahbaz, \& Balsalobre, 2017), the specification of the 
environmental Kuznets curve for the US economy by accounting for the presence of a major renewable energy source and trade openness (Shahbaz et al., 2017). It can be noticed that the author networks have articles about biomass as a source of renewable energy, but these research works are not directed at the transformation of biomass into electricity.

\subsection{Analysis of word occurrences and co-occurrences}

This subsection was elaborated to answer the question "What?", and to do this, the SciMAT software was used. The year range used in Figures 6, 7, and 8 was divided into the same five periods used in Figure 2 (2005-2007, 2008-2010, 20112013, 2014-2016, and 2017-2019). For Figures 6, 7, 8, and 9, a minimum number of words' occurrences was used, making it possible to adequately represent the main words and relationships between them in each period. Table 2 shows these minimum numbers of occurrences. The other steps of the analyzes carried out in SciMAT were the following: (i) unit of analysis: words; (ii) kind of matrix: co-occurrence; (iii) normalization measure: equivalence index; (iv) clustering algorithm: simple centers algorithm; (v) document mappers: core mapper; (vi) quality measures: h-index, g-index, q2-index, hg-index, and average citations; (vii) measures for the longitudinal map: equivalence index.

Table 2. Minimum frequency of words occurrences.

\begin{tabular}{rccc}
\hline Period & Wind energy & Photovoltaic energy & Biomass energy \\
\hline $2005-2007$ & 3 & 4 & 3 \\
$2008-2010$ & 5 & 7 & 3 \\
$2011-2013$ & 5 & 7 & 3 \\
$2014-2016$ & 5 & 8 & 3 \\
$2017-2019$ & 6 & 10 & 4 \\
\hline
\end{tabular}

In evolution maps shown in Figures 6, 7, and 8 there are two types of lines connecting the circles of different periods: the continuous lines indicate a strong and direct connection between the words, while the dashed lines indicate the weaker relationship trends between words. In this way, the word analysis starts with Figure 6, which shows the words map for photovoltaic energy.

In the periods analyzed, renewable resources and solar energy were the strongest words that appear, also having a strong link between themselves. These words also have a connection with the words or terms: alternative energy; electric generators; energy conservation; solar radiation; electricity; renewable energy resources; and energy storage. In the development of these research works, new words appear, such as costs strongly linked to renewable resources (Haseeb et al., 2019) and investments.

Journal of Data and Information Science

http://www.jdis.org https://www.degruyter.com/view/j/jdis 


\section{Research Paper}

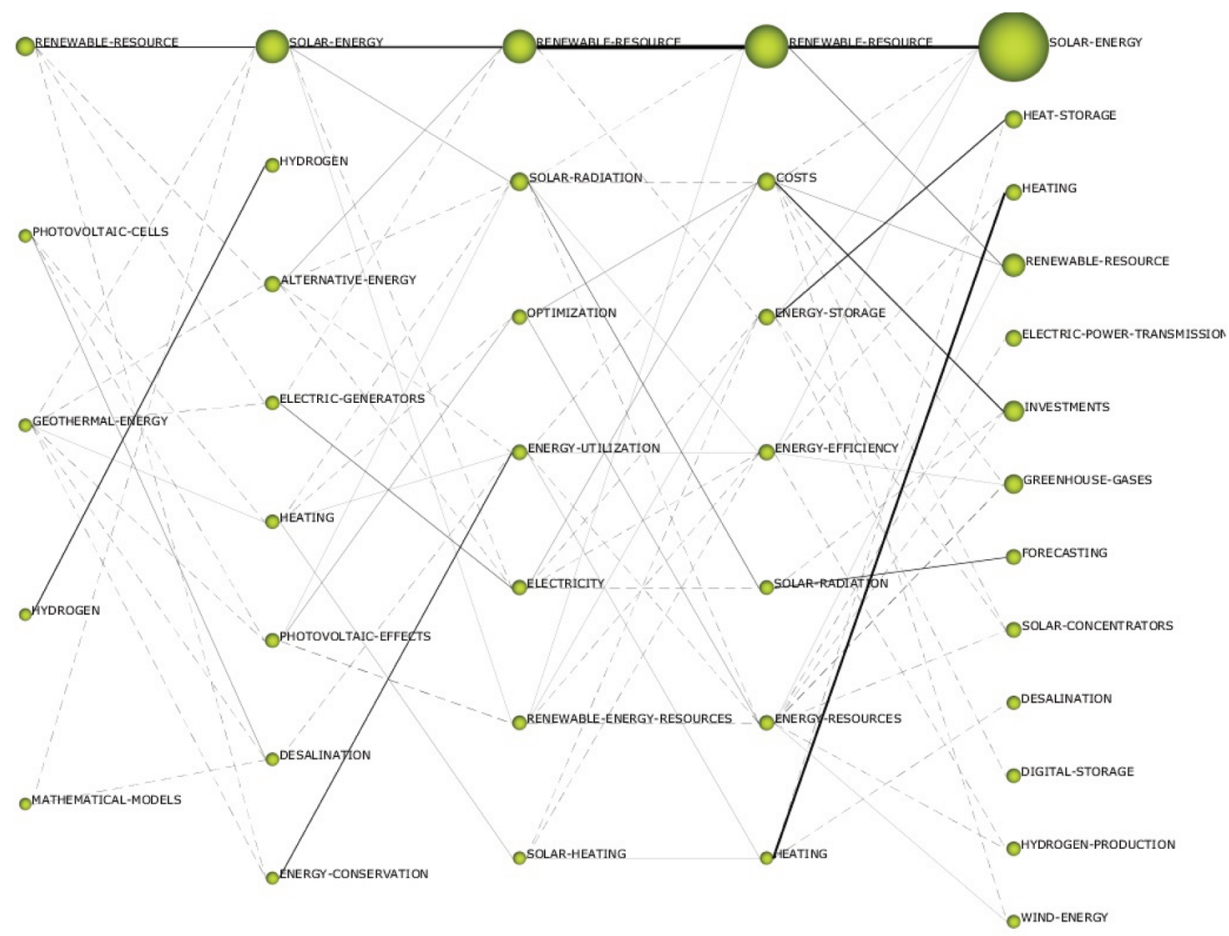

Figure 6. Words map for photovoltaic energy.

Solar radiation is strongly connected with forecasting (Hodge et al., 2018; Orwig et al., 2015), energy storage linked to solar concentrators (Cabeza et al., 2017; Gibb et al., 2018; Jacob et al., 2016; Peiró et al., 2018; Ruiz-Cabañas et al., 2017). Other strong connections are between: energy conservation and energy utilization; energy storage and heat storage; optimization and energy resources; and photovoltaic effects and optimization. Most of the aforementioned co-occurrences can be explained intuitively, but among the less intuitive ones, which can be further explored, the connection between the photovoltaic effects concept and optimization techniques stands out, which may be an interesting research gap. In this map, only the words costs and investments give an idea that there are some articles related to management and decision-making and photovoltaic energy. It can be said that studies concerning the management, decision-making, and performance evaluation of this renewable energy source are attracting more researchers since they have become important to support the correct direction of the investments and the technology implemented.

Information Science

Figure 7 presents the word relations for the fifth period for wind energy research. 


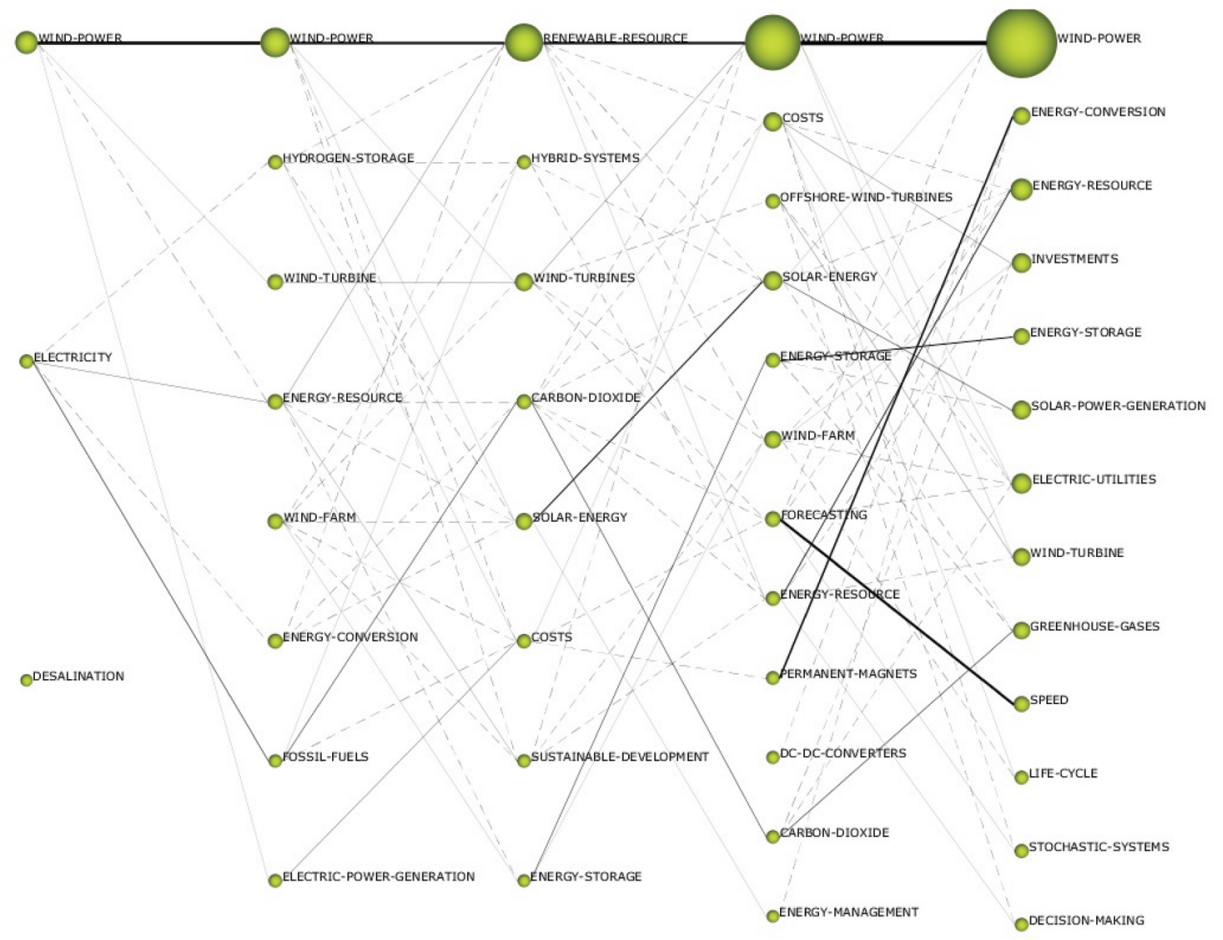

Figure 7. Words map for wind energy.

In this figure, it can be seen that wind power and renewable resources were the most important terms. Besides, there is a trend in periods one and two of talking about wind power and electricity as energy resources, then in period three there begins to be a concern with renewable resources, carbon dioxide, sustainable development (Hu et al., 2017) and costs (Haseeb et al., 2019). In periods four and five there is a shift to discussing technologies such as DC converters, permanent magnets, and wind turbines. In periods four and five there appear the strongest connections between: forecasting and speed; permanent magnets and energy conversion; and carbon dioxide and greenhouse gases. Also, in these periods there begins to be a concern with investments (Martí-Ballester, 2019), energy management, costs, and decision-making. This reveals that over the last ten years, research has been deepening and considering more terms and more of the variables that are part of a system or plant for renewable energy generation. The advancement of studies of the variables involved gives rise to the need for management and control of these variables, and in that sense, the decision-making (Hajibandeh et al., 2018) term only appears in the last period, proving that there is a research gap that is only in the last few years beginning to be explored.

Journal of Data and Information Science

http://www.jdis.org https://www.degruyter.com/view/j/jdis 


\section{Research Paper}

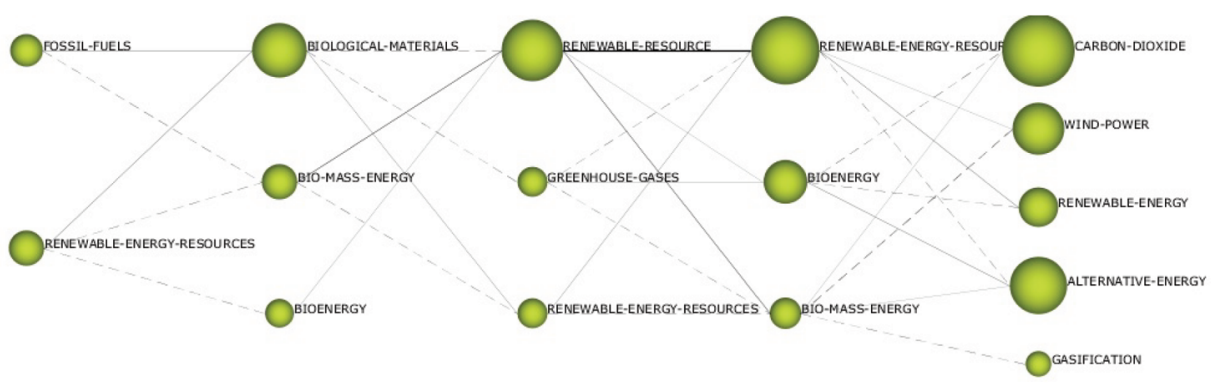

Figure 8. Word map for biomass energy.

Even with less research about biomass as a renewable energy source, a words map was elaborated to show the most important word on this subject. Figure 8 shows this map.

Beginning with the terms of fossil fuels and renewable energy resources, the strongest links were in the sequence with biological materials. However, in the second period, biomass energy and bioenergy have a strong link with renewable resources and renewable energy resources from the third period. Renewable resources from the third period link strongly with renewable energy resources and biomass energy and bioenergy. In the last period the terms carbon dioxide, wind power, renewable energy, and alternative energy appear with relevant links with the fourth period. Considering these word maps, there are no words or terms related to energy management, performance evaluation, or decision-making.

Figure 9 shows two kinds of maps: the cluster's networks and strategic diagrams. On the left side are the cluster's networks elaborated to give an understanding of what words are linked to the centralizing term on each renewable energy source researched, showing how strong the relations are between the terms related to the principal term in the most recent period (2017 to 2019). On the right side, the strategic diagrams are presented to show which keywords have greater centrality and density among the retrieved articles. The terms on the right are those that can be considered more central in most of the research, and the more upward the more densely searched. Therefore, those terms represented in the first quadrant can be considered the most relevant for each area in question.

As shown in the figure, from 2017 until 2019, the centralizing term on photovoltaic energy was "solar-energy", which also appeared 1,201 times according to the strategic diagram. The words and terms with stronger links with solar energy and that represent the consolidation and importance of research in this area are solar power, solar power generation, renewable energies, and photovoltaic systems. There

Journal of Data and is also a strong link between alternative energy and solar power. The words and Information Science terms with thinner connection edges present some tendencies and possible gaps in 

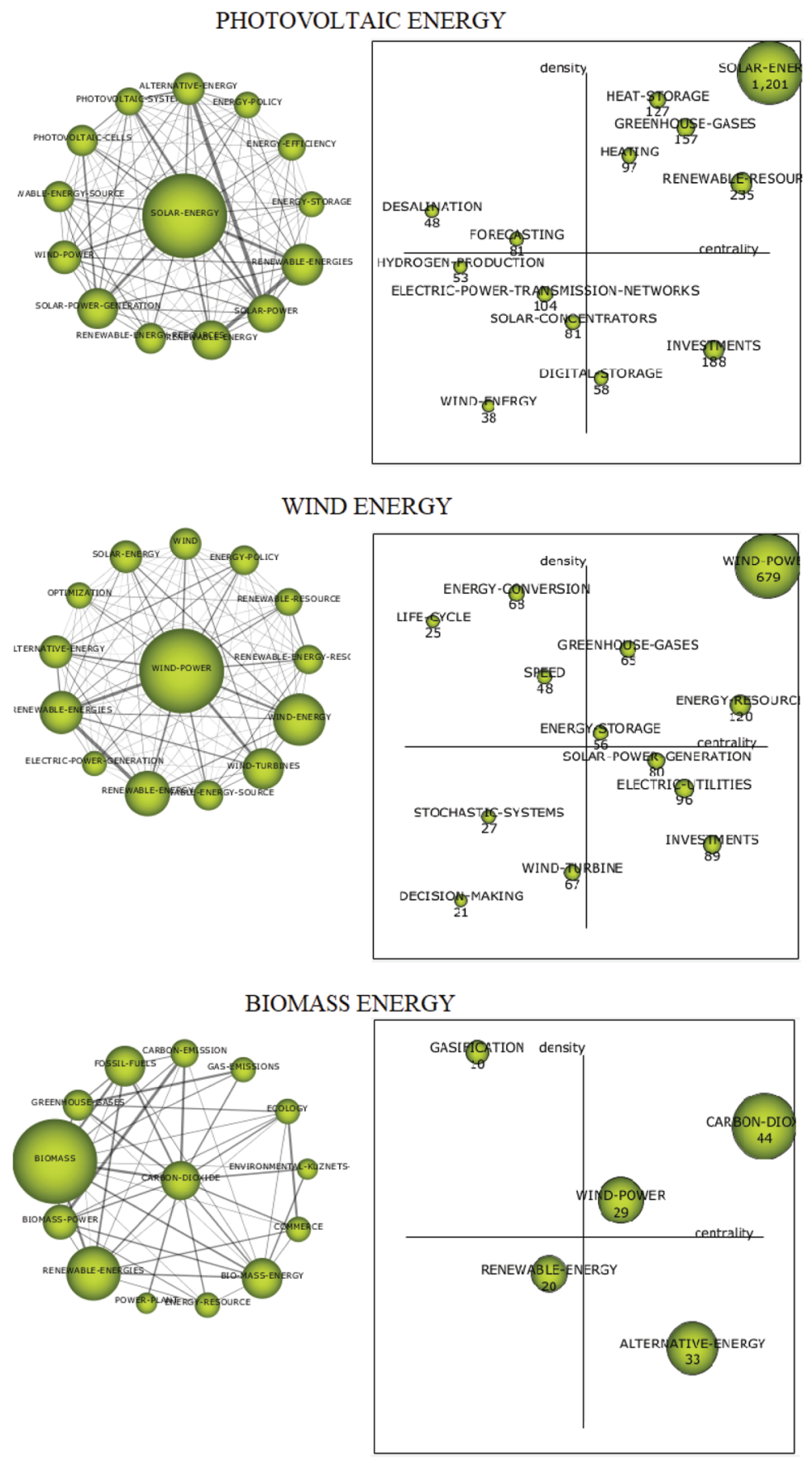

Figure 9. Cluster's network and strategic diagrams about photovoltaic, wind, and biomass energy.

Journal of Data and Information Science http://www.jdis.org https://www.degruvter:com/view/j/jdis 


\section{Research Paper}

this area: energy policy, energy efficiency, energy storage, photovoltaic cells, and alternative energy. From the strategic diagram, it can be seen that the other words which are densely researched are heat-storage, greenhouse-gases, heating, and renewable resources. Considering this analysis, there is a research opportunity regarding energy management and performance evaluation, since words or terms that indicate these study fields do not appear in this figure.

Related to wind energy, the term "wind power", with density 1.0 as the central term of the map, and also with 679 mentions according to the strategic diagram, is linked consistently to the terms renewable energies, wind energy, wind turbines, and alternative energy, proving the consistency and development of these themes in the current period. However, the lower-intensity connections, which show an area of research that can be strengthened, refer to terms such as renewable resource, electric power generation, renewable energy, solar energy, energy policy, renewable energy source, wind, optimization, and electric power generation. Another central and densely researched terms in this theme are greenhouse-gases, energy storage, and energy resources. Among all these terms, energy policy may give an idea in the direction of the gap suggested in this article, since good management of companies is necessary to be able to comply with legislation and policies in the energy sector.

Related to biomass energy, the centralizing term with density 0.78 between 2017 to 2019 was "carbon-dioxide", which appears 44 times according to the strategic diagram. The term carbon dioxide binds strongly to the term biomass. The term biomass, although it appears in numerous articles, does not have a strong connection with other terms, which also explains why the term is not at the center of the diagram, just as it doesn't appear in the strategic diagram. Other strong links are between carbon emission and biomass power, and greenhouse gases and gas emissions, which can be intuitively explained. However, in this diagram, there are no terms or links between terms that lead to an indication of studies related to the management of biomass as a renewable source of electricity.

The word connections presented by SciMAT indicate research trends, which way they are going, and how this can generate new research opportunities. These research opportunities may focus on the most interesting word co-occurrences presented in this article, aiming to deepen the study and to analyze the cause and the specific meaning of these co-occurrences.

\subsection{Geographic analysis}

Figure 10 presents a graphic with the 25 countries/regions with the most publications on renewable energy sources, showing the relations in these publications Information Science among the three sources: photovoltaic, wind, and biomass. 


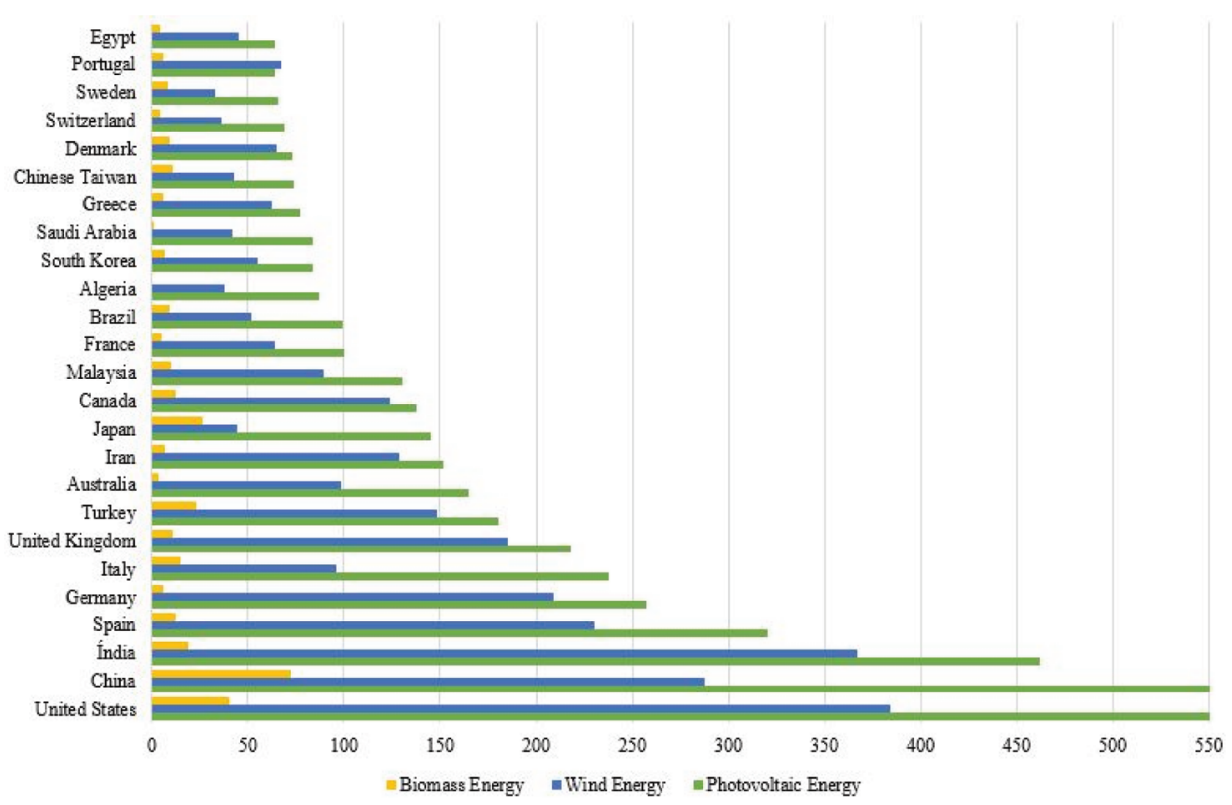

Figure 10. Number of papers published per coutry/region.

Comparing this graphic of the Coutry/region publishing the most research and studies, as confirmed daily, the three countries that lead these studies and research (United States, China, and India) are also the three countries that generate the most jobs in the renewable energy generation plants (IRENA, 2018). Countries in Africa and the Middle East hardly appear at all because, according to IRENA (Whiteman et al., 2018), they contributed only about $3 \%$ of the total renewable energy capacity in 2017.

The origins of the most influential authors in the presented networks are as follows:

- Photovoltaic energy area: Cabeza is from Spain, Hodge and Kroposki are Americans, Rosen is a Canadian researcher, Sopian is from Malaysia, Akbarzadeh is Australian, and Duic is from Croatia.

- Wind energy: Catalão is a Portuguese researcher, Breyer is Finnish, Arroyo and Mañana are Spanish, Senjyu is Japanese, and Wang is Chinese.

- Biomass energy: Tokimatsu is a Japanese researcher, while Wahab, Mohamed, Rasat, Amini, and Ahmad are from Malaysia.

This cross-checking shows that the countries/regions that have the most publications in these areas are also the source of most of the most relevant authors on the topics. It can be highlighted that, although the United States, China, and India

Journal of Data and Information Science

http://www.jdis.org https://www.degruyter.com/view/j/jdis 


\section{Research Paper}

are the top three countries in the number of publications, only three from the 19 most influential authors are from these countries. It can be understood from this that the research on these three sources of renewable energy is widespread and developed in several countries/regions and by several research groups, not being concentrated only on the main research networks. Only Croatia and Finland among the countries/ regions of origin of the main authors of the most influential research networks do not appear among the 25 countries/regions with the most publications in the research areas.

\section{Concluding thoughts}

The results and discussion section presented temporal, author networks, word co-occurrences, and geographic approaches to study scientific development on three renewable energy sources: photovoltaic, wind, and biomass. From these analyses, it can be summarized that the research has shown a considerable development leap from 2008 until reaching its apex in the current period. Several networks of authors are involved in research related to the development of the technologies themselves, many of these networks with links to each other, showing an exchange of knowledge and technology. Besides, the main author networks are the origin of a wide range of articles related to renewable energy technologies, but just a few articles by these authors deal with the management, performance evaluation, and decision-making related to the sources of renewable energy. There are a large number of related words signifying a scientific evolution in broad directions; however, the most commonly used words and terms refer to the renewable energy sources themselves, as well as the technologies used to generate electricity from these sources. Terms and words regarding management, performance evaluation, and decision-making related to these sources only appear occasionally in the period from 2017 to the current one. The United States, China, and India are the three countries producing the most research, and they are also the three countries with major jobs generation in installations of renewable energy sources, and research spreading to countries across continents.

Therefore, considering the scientometric analysis developed, it can be concluded that the purpose of this paper was achieved, since the scientific development of renewable energy sources was mapped, pointing out the principal words, author networks, and countries/regions that produce the most research in the area of photovoltaic energy, wind energy, and biomass energy. From this mapping, it can be said that there is a trend and some interesting opportunities for studies about Information Science management, performance evaluation, and decision-making regarding renewable 
energy sources. Although articles are coming from some of the main networks of authors and the term "decision-making" appears as a trend in the period from 2017 to 2019 , considering the broad scope, research in this area has not yet been consolidated.

Among the computational tools used, the Sci2 Tool provides those who use it with a view of who are the main research groups on certain topics, enabling researchers to develop studies based on already consolidated research. Besides, when visualizing the networks, the researcher can study approaches and readings on a topic, considering different views coming from different research networks. However, there are disadvantages in visualization in the format of networks, as sometimes good research carried out in a more isolated way can be omitted, since smaller networks or individual authors are not privileged in the visualization of networks. Among the maps elaborated through SciMAT, the evolution map brings a view of the trends in a research theme over time, while the view of the centralizing theme in a period shows the most prominent theme in that period. As in the Sci2 Tool, in SciMAT interesting words or terms for research can be omitted because they are not used so often that they appear on maps. It is worth mentioning that both the Sci2 Tool and SciMAT allow other types of analysis not used in this article. The results presented with the aid of the Sci2 Tool and SciMAT in this article are not absolute, but they show possible directions and trends in research based on previously obtained data.

From an academic point of view, this article indicates research opportunities on themes related to management, studies on costs and investments, systemic diagnosis, and performance evaluation for assertive decision-making in businesses on renewable energy sources. Besides, the methodology and tools used in this paper can be applied to other domains and research, guiding new researchers to areas of research that have not yet been explored or little explored, increasing interest and bringing more and more relevance to the academic world.

For companies, this article shows that there is a tendency to implement business management in businesses related to renewable energy sources at different levels, including performance evaluation, aiming at higher performance, more assertive decision making, and adequate use of technical and financial resources. To corroborate these findings, data from world agencies can be used, since they analyze the global production of renewable energies, showing exactly what the research indicates, which is an area that is still growing and developing. Currently, it employs around 10,000,000 people worldwide and is projected to grow exponentially by 2050 (IRENA, 2018), making the management of these systems indispensable.

Journal of Data and Information Science

http://www.jdis.org https://www.degruyter.com/view/j/jdis 


\section{Research Paper}

\section{Limitations and future research}

This paper was limited to the articles indexed in the Scopus database. Another limitation was the broad scope of the discussions that were developed to analyze the scientific production as a whole, without explanations about how each renewable energy works. As future research, we leave a suggestion to analyze the scientific productions that address the issues related to management and decision-making in renewable energy generation.

\section{Acknowledgements}

This work was supported by the Conselho Nacional de Desenvolvimento Científico e Tecnológico (CNPq) [grant numbers 142448/2018-4, 308723/2017-1, 311926/2017-7 and 465640/2014-1], Coordenação de Aperfeiçoamento de Pessoal de Nível Superior (CAPES) [grant number 23038.000776/2017-54] and Fundação de Amparo à Pesquisa do Estado do Rio Grande do Sul (FAPERGS) [grant number 17/2551-0000517-1]. Baierle were supported by a post doc grant of CAPES - Brazil (CAPES process Baierle No. 88887.464876/2019-00). The authors thank to CNPq, CAPES, FAPERGS and Institutos Nacionais de Ciência e Tecnologia - Geração Distribuída (INCT-GD) for supporting this research.

\section{Author contributions}

Jones Luís Schaefer (engjlschaefer@yahoo.com.br) proposed the original idea, collected and analyzed the data, and wrote the manuscript; Julio Cezar Mairesse Siluk (jsiluk@ufsm.br) analyzed the findings and reviewed the manuscript; Ismael Cristofer Baierle (ismaelbaierle@ hotmail.com) analyzed the findings, wrote and reviewed the manuscript; Elpidio Oscar Benitez Nara (elpidio.nara@outlook.com) reviewed the manuscript.

\section{References}

Abramo, G. (2018). Revisiting the scientometric conceptualization of impact and its measurement. Journal of Informetrics, 12(3), 590-597. https://doi.org/10.1016/j.joi.2018.05.001

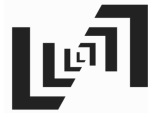

Journal of Data and Information Science
Akbarzadeh, A., Johnson, P., \& Singh, R. (2009). Examining potential benefits of combining a chimney with a salinity gradient solar pond for production of power in salt affected areas. Solar Energy, 83(8), 1345-1359. https://doi.org/10.1016/j.solener.2009.02.010

Alcaraz, A., Montalà, M., Cortina, J.L., Akbarzadeh, A., Aladjem, C., Farran, A., \& Valderrama, C. (2018). Design, construction, and operation of the first industrial salinity-gradient solar pond in Europe: An efficiency analysis perspective. Solar Energy, 164, 316-326. https://doi. org/10.1016/j.solener.2018.02.053

Arroyo, A., Castro, P., Manana, M., Domingo, R., \& Laso, A. (2018). CO2 footprint reduction and efficiency increase using the dynamic rate in overhead power lines connected to wind farms. 
Applied Thermal Engineering, 130, 1156-1162. https://doi.org/10.1016/j.applthermaleng. 2017.11.095

Ayyarao, T.S.L.V. (2019). Modified vector controlled DFIG wind energy system based on barrier function adaptive sliding mode control. Protection and Control of Modern Power Systems, 4(1), 1-8. https://doi.org/10.1186/s41601-019-0119-3

Azhari, A.W., Sopian, K., Zaharim, A., \& Al Ghoul, M. (2008). A new approach for predicting solar radiation in tropical environment using satellite images - Case study of Malaysia. WSEAS Transactions on Environment and Development, 4(4), 373-378.

Baierle, I.C., Schaefer, J.L., Sellitto, M.A., Fava, L.P., Furtado, J.C., \& Nara, E.O.B. (2020). Moona software for survey classification and evaluation of criteria to support decisionmaking for properties portfolio. International Journal of Strategic Property Management, 24(4), 226-236. https://doi.org/10.3846/ijspm.2020.12338

Bakhtyar, B., Saadatian, O., Alghoul, M.A., Ibrahim, Y., \& Sopian, K. (2015). Solar electricity market in Malaysia: A review of feed-in tariff policy. Environmental Progress and Sustainable Energy, 34(2), 600-606. https://doi.org/10.1002/ep.12023

Bakhtyar, B., Sopian, K., Zaharim, A., Salleh, E., \& Lim, C.H. (2013). Potentials and challenges in implementing feed-in tariff policy in Indonesia and the Philippines. Energy Policy, 60, 418-423. https://doi.org/10.1016/j.enpol.2013.05.034

Battaglini, A., Komendantova, N., Brtnik, P., \& Patt, A. (2012). Perception of barriers for expansion of electricity grids in the European Union. Energy Policy, 47, 254-259. https://doi. org/10.1016/j.enpol.2012.04.065

Batty, M., \& Gleeson, B. (2003). The geography of scientific citation + The Difference that Planning Makes. Environment and Planning A, 35, 761-770. https://doi.org/10.1068/a3505com

Ben Jebli, M., Ben Youssef, S., \& Apergis, N. (2019). The dynamic linkage between renewable energy, tourism, CO 2 emissions, economic growth, foreign direct investment, and trade. Latin American Economic Review, 28, 2. https://doi.org/10.1186/s40503-019-0063-7

Benchaabane, Y., Silva, R.E., Ibrahim, H., Ilinca, A., Chandra, A., \& Rousse, D.R. (2019). Computer Model for Financial, Environmental and Risk Analysis of a Wind-Diesel Hybrid System with Compressed Air Energy Storage. Energies, 12(21), 4054. https://doi.org/10.3390/ en12214054

Bernad, F., Casas, S., Gibert, O., Akbarzadeh, A., Cortina, J.L., \& Valderrama, C. (2013). Salinity gradient solar pond: Validation and simulation model. Solar Energy, 98(Part C), 366-374. https://doi.org/10.1016/j.solener.2013.10.004

Biddinika, M.K., Diponegoro, A.M., Ali, R.M., Rosyadi, R.I., Tokimatsu, K., \& Takahashi, F. (2017). Survey on readability of online information for upgrading understandability of biomass energy technology. Journal of Material Cycles and Waste Management, 19(3), 1069-1076. https://doi.org/10.1007/s10163-017-0596-2

Börner, K., Chen, C., \& Boyack, K.W. (2005). Visualizing knowledge domains. Annual Review of Information Science and Technology,37(1), 179-255.https://doi.org/10.1002/aris.1440370106

Börner, K., Klavans, R., Patek, M., Zoss, A.M., Biberstine, J.R., Light, R.P., Larivière, V., \& Boyack, K.W. (2012). Design and update of a classification system: The ucsd map of science. PLoS ONE, 7(7), e39464. https://doi.org/10.1371/journal.pone.0039464

Busuttil, A., Krajačić, G., \& Duić, N. (2008). Energy scenarios for Malta. International Journal of Hydrogen Energy, 33(16), 4235-4246. https://doi.org/10.1016/j.ijhydene.2008.06.010

Journal of Data and Information Science

http://www.jdis.org https://www.degruyter:com/view/j/jdis 


\section{Research Paper}

Cabeza, L.F., Galindo, E., Prieto, C., Barreneche, C., \& Inés Fernández, A. (2015). Key performance indicators in thermal energy storage: Survey and assessment. Renewable Energy, 83, 820-827. https://doi.org/10.1016/j.renene.2015.05.019

Cabeza, L.F., Solé, A., Fontanet, X., Barreneche, C., Jové, A., Gallas, M., Prieto, C., \& Fernández, A.I. (2017). Thermochemical energy storage by consecutive reactions for higher efficient concentrated solar power plants (CSP): Proof of concept. Applied Energy, 185(Part 1), 836-845. https://doi.org/10.1016/j.apenergy.2016.10.093

Carrington, P., Scott, J., \& Wasserman, S. (2005). Models and methods in social network analysis. CambridgeUniversity Press. https://books.google.com.br/books?hl=pt-BR\&lr=\&id=4Ty5xP KcpAC\&oi $=$ fnd\&pg $=$ PR9\&dq $=\% 22$ Models + and + methods + in + social + network + analysis $\%$ 22\&ots=9NJLv7tbJ3\&sig=nBeqcDbBSs5PmezJX3DaVorpS00

Chakraborty, S., Senjyu, T., Saber, A.Y., Yona, A., \& Funabashi, T. (2009). Optimal thermal unit commitment integrated with renewable energy sources using advanced particle swarm optimization. IEEJ Transactions on Electrical and Electronic Engineering, 4(5), 609-617. https://doi.org/10.1002/tee.20453

Chel, A., \& Kaushik, G. (2018). Renewable energy technologies for sustainable development of energy efficient building. Alexandria Engineering Journal, 57(2), 655-669. https://doi.org/ 10.1016/j.aej.2017.02.027

Chen, C., Li, Y., Song, J., Yang, Z., Kuang, Y., Hitz, E., Jia, C., Gong, A., Jiang, F., Zhu, J.Y., Yang, B., Xie, J., \& Hu, L. (2017). Highly Flexible and Efficient Solar Steam Generation Device. Advanced Materials, 29(30), 1701756. https://doi.org/10.1002/adma.201701756

Child, M., Ilonen, R., Vavilov, M., Kolehmainen, M., \& Breyer, C. (2019). Scenarios for sustainable energy in Scotland. Wind Energy, 22(5), 666-684. https://doi.org/10.1002/we.2314

Child, M., Nordling, A., \& Breyer, C. (2017). Scenarios for a sustainable energy system in the Åland Islands in 2030. Energy Conversion and Management, 137, 49-60. https://doi.org/ 10.1016/j.enconman.2017.01.039

Cobo, M.J., López-Herrera, A.G., Herrera-Viedma, E., \& Herrera, F. (2011a). An approach for detecting, quantifying, and visualizing the evolution of a research field: A practical application to the Fuzzy Sets Theory field. Journal of Informetrics, 5(1), 146-166. https://doi.org/ 10.1016/j.joi.2010.10.002

Cobo, M.J., López-Herrera, A.G., Herrera-Viedma, E., \& Herrera, F. (2011b). Science mapping software tools: Review, analysis, and cooperative study among tools. Journal of the American Society for Information Science and Technology, 62(7), 1382-1402. https://doi.org/10.1002/ asi. 21525

【Lัง

Cobo, M.J., Lõpez-Herrera, A.G., Herrera-Viedma, E., \& Herrera, F. (2012). SciMAT: A new science mapping analysis software tool. Journal of the American Society for Information Science and Technology, 63(8), 1609-1630. https://doi.org/10.1002/asi.22688

Cobo, M.J., Martínez, M.A., Gutiérrez-Salcedo, M., Fujita, H., \& Herrera-Viedma, E. (2015). 25 years at Knowledge-Based Systems: A bibliometric analysis. Knowledge-Based Systems, 80, 3-13. https://doi.org/10.1016/j.knosys.2014.12.035

Journal of Data and Information Science

Cook, D., \& Holder, L. (2006). Mining graph data. John Wiley and Sons Inc. https://books.google. com.br/books?hl=pt-BR\&lr=\&id=bHGy0_H0g8QC\&oi=fnd\&pg=PR7\&dq=cook $+\% 22 \mathrm{Mini}$ ng+graph+data\%22\&ots=FtWbVNf0hQ\&sig=H3zgSQPkN4YwbubpOy7kBjiKvTU 
Da Costa, M.B., Dos Santos, L.M.A.L., Schaefer, J.L., Baierle, I.C., \& Nara, E.O.B. (2019). Industry 4.0 technologies basic network identification. Scientometrics, 121(2), 977-994. https://doi.org/10.1007/s11192-019-03216-7

Daghigh, R., Ibrahim, A., Jin, G.L., Ruslan, M.H., \& Sopian, K. (2011). Predicting the performance of amorphous and crystalline silicon based photovoltaic solar thermal collectors. Energy Conversion and Management, 52(3), 1741-1747. https://doi.org/10.1016/j.enconman.2010. 10.039

De Solla Price, D., \& Gürsey, S. (1975). Studies in Scientometrics I Transience and Continuance in Scientific Authorship. Ciência Da Informação, 4(1).

Dominković, D.F., Bačeković, I., Ćosić, B., Krajačić, G., Pukšec, T., Duić, N., \& Markovska, N. (2016). Zero carbon energy system of South East Europe in 2050. Applied Energy, 184, 1517-1528. https://doi.org/10.1016/j.apenergy.2016.03.046

Du, E., Zhang, N., Hodge, B.M., Kang, C., Kroposki, B., \& Xia, Q. (2018). Economic justification of concentrating solar power in high renewable energy penetrated power systems. Applied Energy, 222, 649-661. https://doi.org/10.1016/j.apenergy.2018.03.161

Du, E., Zhang, N., Hodge, B.M., Wang, Q., Lu, Z., Kang, C., Kroposki, B., \& Xia, Q. (2019). Operation of a high renewable penetrated power system with CSP plants: A look-ahead stochastic unit commitment model. IEEE Transactions on Power Systems, 34(1), 140-151. https://doi.org/10.1109/TPWRS.2018.2866486

Ducom, G., Gautier, M., Pietraccini, M., Tagutchou, J.P., Lebouil, D., \& Gourdon, R. (2020). Comparative analyses of three olive mill solid residues from different countries and processes for energy recovery by gasification. Renewable Energy, 145, 180-189. https://doi.org/ 10.1016/j.renene.2019.05.116

Fagiano, L., \& Schnez, S. (2017). On the take-off of airborne wind energy systems based on rigid wings. Renewable Energy, 107, 473-488. https://doi.org/10.1016/j.renene.2017.02.023

Fagiano, Lorenzo, Milanese, M., \& Piga, D. (2010). High-altitude wind power generation. IEEE Transactions on Energy Conversion, 25(1), 168-180. https://doi.org/10.1109/TEC.2009. 2032582

Fayaz, H., Rahim, N.A., Hasanuzzaman, M., Nasrin, R., \& Rivai, A. (2019). Numerical and experimental investigation of the effect of operating conditions on performance of PVT and PVT-PCM. Renewable Energy, 143, 827-841. https://doi.org/10.1016/j.renene.2019.05.041

Garfield, E. (1994). Scientography: Mapping the tracks of science. Contents: Social \& Behavioral Sciences, 7(45), 5-10.

Garner, J., Porter, A.L., Leidolf, A., \& Baker, M. (2020). Measuring and visualizing research collaboration and productivity. Journal of Data and Information Science, 3(1), 54-81. https:// doi.org/10.2478/jdis-2018-0004

Gibb, D., Johnson, M., Romaní, J., Gasia, J., Cabeza, L.F., \& Seitz, A. (2018). Process integration of thermal energy storage systems - Evaluation methodology and case studies. Applied Energy, 230, 750-760. https://doi.org/10.1016/j.apenergy.2018.09.001

Granovskii, M., Dincer, I., \& Rosen, M.A. (2007). Exergetic life cycle assessment of hydrogen production from renewables. Journal of Power Sources, 167(2), 461-471. https://doi.org/ 10.1016/j.jpowsour.2007.02.031

Guler, A.T., Waaijer, C.J.F., Mohammed, Y., \& Palmblad, M. (2016). Automating bibliometric analyses using Taverna scientific workflows: A tutorial on integrating Web Services. Journal of Informetrics, 10(3), 830-841. https://doi.org/10.1016/j.joi.2016.05.002

Journal of Data and Information Science

http://www.jdis.org https://www.degruyter.com/view/j/jdis 


\section{Research Paper}

Hacatoglu, K., Dincer, I., \& Rosen, M.A. (2011). Exergy analysis of a hybrid solar hydrogen system with activated carbon storage. International Journal of Hydrogen Energy, 36(5), 3273-3282. https://doi.org/10.1016/j.ijhydene.2010.12.034

Hajibandeh, N., Shafie-khah, M., Osório, G.J., Aghaei, J., \& Catalão, J.P.S. (2018). A heuristic multi-objective multi-criteria demand response planning in a system with high penetration of wind power generators. Applied Energy, 212, 721-732. https://doi.org/10.1016/j.apenergy. 2017.12.076

Hanel, M., \& Escobar, R. (2013). Influence of solar energy resource assessment uncertainty in the levelized electricity cost of concentrated solar power plants in Chile. Renewable Energy, 49, 96-100. https://doi.org/10.1016/j.renene.2012.01.056

Haseeb, M., Abidin, I.S.Z., Hye, Q.M.A., \& Hartani, N.H. (2019). The impact of renewable energy on economic well-being of Malaysia: Fresh evidence from auto regressive distributed lag bound testing approach. International Journal of Energy Economics and Policy, 9(1), 269-275. https://doi.org/10.32479/ijeep.7229

Hassan, A., Wahab, A., Qasim, M.A., Janjua, M.M., Ali, M.A., Ali, H.M., Jadoon, T.R., Ali, E., Raza, A., \& Javaid, N. (2020). Thermal management and uniform temperature regulation of photovoltaic modules using hybrid phase change materials-nanofluids system. Renewable Energy, 145, 282-293. https://doi.org/10.1016/j.renene.2019.05.130

Hodge, B.M., Brancucci Martinez-Anido, C., Wang, Q., Chartan, E., Florita, A., \& Kiviluoma, J. (2018). The combined value of wind and solar power forecasting improvements and electricity storage. Applied Energy, 214, 1-15. https://doi.org/10.1016/j.apenergy.2017.12.120

Hu, C., Chen, X., Dai, Q., Wang, M., Qu, L., \& Dai, L. (2017). Earth-abundant carbon catalysts for renewable generation of clean energy from sunlight and water. Nano Energy, 41, 367-376. https://doi.org/10.1016/j.nanoen.2017.09.029

IRENA. (2018). Renewable Energy and Jobs - Annual Review 2018. In /publications/2018/May/ Renewable-Energy-and-Jobs-Annual-Review-2018. https:/www.irena.org/publications/2018/ May/Renewable-Energy-and-Jobs-Annual-Review-2018

Jacob, R., Belusko, M., Inés Fernández, A., Cabeza, L.F., Saman, W., \& Bruno, F. (2016). Embodied energy and cost of high temperature thermal energy storage systems for use with concentrated solar power plants. Applied Energy, 180, 586-597. https://doi.org/10.1016/ j.apenergy.2016.08.027

Khalid, F., Dincer, I., \& Rosen, M.A. (2015). Energy and exergy analyses of a solar-biomass integrated cycle for multigeneration. Solar Energy, 112, 290-299. https://doi.org/10.1016/ j.solener.2014.11.027

Kipper, L.M., Furstenau, L.B., Hoppe, D., Frozza, R., \& Iepsen, S. (2020). Scopus scientific mapping production in industry 4.0 (2011-2018): a bibliometric analysis. International Journal of Production Research, 58(6), 1605-1627. https://doi.org/10.1080/00207543.2019. 1671625

Komendantova, N., Patt, A., Barras, L., \& Battaglini, A. (2012). Perception of risks in renewable energy projects: The case of concentrated solar power in North Africa. Energy Policy, 40(1), 103-109. https://doi.org/10.1016/j.enpol.2009.12.008

Krajačić, G., Vujanović, M., Duić, N., Kılkış, Ş., Rosen, M.A., \& Ahmad Al-Nimr, M. (2018). Integrated approach for sustainable development of energy, water and environment systems.

Journal of Data and Information Science
Energy Conversion and Management, 159, 398-412. https://doi.org/10.1016/j.enconman. 2017.12.016 
Kumar, R.S., \& Kaliyaperumal, K. (2015). A scientometric analysis of mobile technology publications. Scientometrics, 105, 921-939. https://doi.org/10.1007/s11192-015-1710-7

Leblanc, J., Andrews, J., \& Akbarzadeh, A. (2010). Low-temperature solar-thermal multi-effect evaporation desalination systems. International Journal of Energy Research, 34(5), 393-403. https://doi.org/10.1002/er.1642

Letcher, T.M. (2018). Why Solar Energy? In A Comprehensive Guide to Solar Energy Systems (pp. 3-16). Elsevier. https://doi.org/10.1016/b978-0-12-811479-7.00001-4

Leydesdorff, L., \& Persson, O. (2010). Mapping the geography of science: Distribution patterns and networks of relations among cities and institutes. Journal of the American Society for Information Science and Technology, 61(8), 1622-1634. https://doi.org/10.1002/asi.21347

Light, R.P., Polley, D.E., \& Börner, K. (2014). Open data and open code for big science of science studies. Scientometrics, 101, 1535-1551. https://doi.org/10.1007/s11192-014-1238-2

Liu, X., Feng, X., \& He, Y. (2019). Rapid discrimination of the categories of the biomass pellets using laser-induced breakdown spectroscopy. Renewable Energy, 143, 176-182. https://doi. org/10.1016/j.renene.2019.04.137

Longo, M., Foiadelli, F., \& Yaïci, W. (2019). Simulation and optimisation study of the integration of distributed generation and electric vehicles in smart residential district. International Journal of Energy and Environmental Engineering, 10(3), 271-285. https://doi.org/10.1007/ s40095-019-0301-4

Lopez-Rey, A., Campinez-Romero, S., Gil-Ortego, R., \& Colmenar-Santos, A. (2019). Evaluation of supply-demand adaptation of photovoltaic-wind hybrid plants integrated into an urban environment. Energies, 12(9), 1780. https://doi.org/10.3390/en12091780

Madrazo, A., González, A., Martínez, R., Domingo, R., Mañana, M., Arroyo, A., Castro, P.B., Silió, D., \& Lecuna, R. (2015). Analysis of a real case of ampacity management in a $132 \mathrm{kV}$ network integrating high rates of wind energy. Renewable Energy and Power Quality Journal, 1(13), 797-800. https://doi.org/10.24084/repqj13.513

Madrazo, A., González, A., Martínez, R., Mañana, M., Hervás, E., Arroyo, A., Castro, P.B., \& Silió, D. (2013). Increasing grid integration of wind energy by using ampacity techniques. Renewable Energy and Power Quality Journal, 1(11), 1121-1124. https://doi.org/10.24084/ repqj11.549

Maleki, A., Rosen, M.A., \& Pourfayaz, F. (2017). Optimal operation of a grid-connected hybrid renewable energy system for residential applications. Sustainability (Switzerland), 9(8), 1314. https://doi.org/10.3390/su9081314

Martí-Ballester, C.P. (2019). Do European renewable energy mutual funds foster the transition to a low-carbon economy? Renewable Energy, 143, 1299-1309. https://doi.org/10.1016/ j.renene.2019.05.095

Martínez, M.A., Cobo, M.J., Herrera, M., \& Herrera-Viedma, E. (2015). Analyzing the Scientific Evolution of Social Work Using Science Mapping. Research on Social Work Practice, 25(2), 257-277. https://doi.org/10.1177/1049731514522101

Mena, R., Escobar, R., Lorca, Negrete-Pincetic, M., \& Olivares, D. (2019). The impact of concentrated solar power in electric power systems: A Chilean case study. Applied Energy, 235, 258-283. https://doi.org/10.1016/j.apenergy.2018.10.088

Moeller, C., Meiss, J., Mueller, B., Hlusiak, M., Breyer, C., Kastner, M., \& Twele, J. (2014). Transforming the electricity generation of the Berlin-Brandenburg region, Germany. Renewable Energy, 72, 39-50. https://doi.org/10.1016/j.renene.2014.06.042

Journal of Data and Information Science

http://www.jdis.org https://www.degruyter.com/view/j/jdis 


\section{Research Paper}

Nara, E.O.B., Schaefer, J.L., de Moraes, J., Tedesco, L.P.C., Furtado, J.C., \& Baierle, I.C. (2019). Sourcing research papers on small- and medium-sized enterprises' competitiveness: An approach based on authors' networks. Revista Espanola de Documentacion Cientifica, 42(2), e230. https://doi.org/10.3989/redc.2019.2.1602

Nazri, N.S., Fudholi, A., Ruslan, M.H., \& Sopian, K. (2018). Mathematical Modeling of Photovoltaic Thermal-Thermoelectric (PVT-TE) Air Collector. International Journal of Power Electronics and Drive System (IJPEDS), 9(2), 795-802. https://doi.org/10.11591/ ijpeds.v9.i2.pp795-802

Newman, M.E.J. (2001a). Scientific collaboration networks. I. Network construction and fundamental results. Physical Review E - Statistical Physics, Plasmas, Fluids, and Related Interdisciplinary Topics, 64(1), 016131. https://doi.org/10.1103/PhysRevE.64.016131

Newman, M.E.J. (2001b). Scientific collaboration networks. II. Shortest paths, weighted networks, and centrality. Physical Review E - Statistical Physics, Plasmas, Fluids, and Related Interdisciplinary Topics, 64(1), 016132. https://doi.org/10.1103/PhysRevE.64.016132

Orwig, K.D., Ahlstrom, M.L., Banunarayanan, V., Sharp, J., Wilczak, J.M., Freedman, J., Haupt, S.E., Cline, J., Bartholomy, O., Hamann, H.F., Hodge, B.M., Finley, C., Nakafuji, D., Peterson, J.L., Maggio, D., \& Marquis, M. (2015). Recent trends in variable generation forecasting and its value to the power system. IEEE Transactions on Sustainable Energy, 6(3), 924-933. https://doi.org/10.1109/TSTE.2014.2366118

Osório, G.J., Lujano-Rojas, J.M., Matias, J.C.O., \& Catalão, J.P.S. (2015). A new scenario generation-based method to solve the unit commitment problem with high penetration of renewable energies. International Journal of Electrical Power and Energy Systems, 64, 1063-1072. https://doi.org/10.1016/j.ijepes.2014.09.010

Othman, M.Y., Ibrahim, A., Jin, G.L., Ruslan, M.H., \& Sopian, K. (2013). Photovoltaic-thermal (PV/T) technology - The future energy technology. Renewable Energy, 49, 171-174. https:// doi.org/10.1016/j.renene.2012.01.038

Oyedepo, S.O., Adaramola, M.S., \& Paul, S.S. (2012). Analysis of wind speed data and wind energy potential in three selected locations in South-East Nigeria. International Journal of Energy and Environmental Engineering, 3(1), 1-11. https://doi.org/10.1186/2251-6832-3-7

Parliament, E. (2009). Directiva 2009/28/CE do Parlamento Europeu e do Conselho. Jornal Oficial Da União Europeia, 47. https://eur-lex.europa.eu/legal-content/PT/TXT/PDF/?uri=CELEX: 32009L0028\& from $=\mathrm{EN}$

Peiró, G., Prieto, C., Gasia, J., Jové, A., Miró, L., \& Cabeza, L.F. (2018). Two-tank molten salts thermal energy storage system for solar power plants at pilot plant scale: Lessons learnt and recommendations for its design, start-up and operation. Renewable Energy, 121, 236-248. https://doi.org/10.1016/j.renene.2018.01.026

【ัเงฺ|

Pfeifer, A., Krajačić, G., Ljubas, D., \& Duić, N. (2019). Increasing the integration of solar photovoltaics in energy mix on the road to low emissions energy system - Economic and environmental implications. Renewable Energy, 143, 1310-1317. https://doi.org/10.1016/ j.renene.2019.05.080

Poole, A.D., Barnett, A.M., Boes, E., Weinberg, C.J., Ogden, J.M., Carlson, D.E., ..., \& Nitsch, J. (1993). Renewable Energy: Sources for fuels and electricity. Island Press. https://books. google.com.br/books?hl=pt-BR\&lr=\&id=40XtqVMRxOUC\&oi=fnd\&pg=PA1\&dq=Grubb,

Journal of Data and Information Science + M. + J., $+\% 26+$ Meyer, + N. + I. $+(1993) .+$ Wind + resources. + Renewable+Energy: + Sources + for + Fuels + and + Electricity, $+198 . \&$ ots $=j 0 I t F \_m P r \& s i g=D F z X 4 t T y S 4 d s x C Y \_i K y j D O n C R c 8$ 
Rasat, M.S.M., Wahab, R., Mohamed, M., Iqbal Ahmad, M., Hazim Mohamad Amini, M., Mohd Nazri Wan Abdul Rahman, W., Khairul Azhar Abdul Razab, M., Ahmad Mohd Yunus, A., Kelantan, M., \& Campus, J. (2016). Preliminary study on properties of small diameter wild leucaena leucocephala species as potential biomass energy sources. ARPN Journal of Engineering and Applied Sciences, 11(9). www.arpnjournals.com

Ren, C., An, N., Wang, J., Li, L., Hu, B., \& Shang, D. (2014). Optimal parameters selection for BP neural network based on particle swarm optimization: A case study of wind speed forecasting. Knowledge-Based Systems, 56, 226-239. https://doi.org/10.1016/j.knosys.2013.11.015

Rezaie, B., Reddy, B.V., \& Rosen, M.A. (2018). Exergy Assessment of a Solar-Assisted District Energy System. The Open Fuels \& Energy Science Journal, 11, 30. https://doi.org/10.2174/ $1876973 \times 01811010030$

Rodrigues, E.M.G., Osório, G.J., Godina, R., Bizuayehu, A.W., Lujano-Rojas, J.M., Matias, J.C.O., \& Catalão, J.P.S. (2015). Modelling and sizing of NaS (sodium sulfur) battery energy storage system for extending wind power performance in Crete Island. Energy, 90 Part 2, 1606-1617. https://doi.org/10.1016/j.energy.2015.06.116

Rosa, C.B., Rediske, G., Rigo, P.D., Wendt, J.F.M., Michels, L., \& Siluk, J.C.M. (2018). Development of a computational tool for measuring organizational competitiveness in the photovoltaic power plants. Energies, 11(4). https://doi.org/10.3390/en11040867

Roselli, C., Diglio, G., Sasso, M., \& Tariello, F. (2019). A novel energy index to assess the impact of a solar PV-based ground source heat pump on the power grid. Renewable Energy, 143, 488-500. https://doi.org/10.1016/j.renene.2019.05.023

Ruiz-Cabañas, F.J., Prieto, C., Madina, V., Fernández, A.I., \& Cabeza, L.F. (2017). Materials selection for thermal energy storage systems in parabolic trough collector solar facilities using high chloride content nitrate salts. Solar Energy Materials and Solar Cells, 163, 134-147. https://doi.org/10.1016/j.solmat.2017.01.028

Rukman, N.S.B., Fudholi, A., Taslim, I., Indrianti, M.A., Manyoe, I.N., Lestari, U., \& Sopian, K. (2019). Energy and exergy efficiency of water-based photovoltaic thermal (PVT) systems: An overview. International Journal of Power Electronics and Drive Systems, 10(2), 987-994. https://doi.org/10.11591/ijpeds.v10.i2.pp987-994

Sakamoto, R., Senjyu, T., Kaneko, T., Urasaki, N., Takagi, T., \& Sugimoto, S. (2008). Output power leveling of wind turbine generator by pitch angle control using $\mathrm{H} \infty$ control. Electrical Engineering in Japan (English Translation of Denki Gakkai Ronbunshi), 162(4), 17-24. https://doi.org/10.1002/eej.20657

Salameh, Z., New York, L., \& Diego, S. (2014). Renewable Energy System Design. Academic Press. http://elsevier.com/

Sassmannshausen, S.P., \& Volkmann, C. (2018). The Scientometrics of Social Entrepreneurship and Its Establishment as an Academic Field. Journal of Small Business Management, 56(2), 251-273. https://doi.org/10.1111/jsbm.12254

Schaefer, J.L., Siluk, J.C.M., Carvalho, P.S. de, Renes Pinheiro, J., \& Schneider, P.S. (2020). Management Challenges and Opportunities for Energy Cloud Development and Diffusion. Energies, 13(16), 4048. https://doi.org/10.3390/en13164048

Sci2 Tool. (2019). A Tool for Science of Science Research and Practice. https://sci2.cns.iu.edu/ user/index.php

Journal of Data and Information Science

http://www.jdis.org https://www.degruyter.com/view/j/jdis 


\section{Research Paper}

Senjyu, T., Sakamoto, R., Urasaki, N., Higa, H., Uezato, K., \& Funabashi, T. (2006). Output power control of wind turbine generator by pitch angle control using minimum variance control. Electrical Engineering in Japan (English Translation of Denki Gakkai Ronbunshi), 154(2), 10-18. https://doi.org/10.1002/eej.20247

Shahbaz, M., Solarin, S.A., Hammoudeh, S., \& Shahzad, S.J.H. (2017). Bounds testing approach to analyzing the environment Kuznets curve hypothesis with structural beaks: The role of biomass energy consumption in the United States. Energy Economics, 68, 548-565. https:// doi.org/10.1016/j.eneco.2017.10.004

Sharizal Sirrajudin, M., Sukhairi Mat Rasat, M., Wahab, R., Hazim Mohamad Amini, M., Mohamed, M., Iqbal Ahmad, M., Moktar, J., Azhar Ibrahim, M., Kelantan, M., \& Campus, J. (2016). Enhancing the Energy Properties of Fugel Pellets from Oil Palm Fronds of Agricultural Residues by Mixing with Glycerin. 11(9). www.arpnjournals.com

Singh, B., Baharin, N.A., Remeli, M.F., Oberoi, A., Date, A., \& Akbarzadeh, A. (2017). Experimental Analysis of Thermoelectric Heat Exchanger for Power Generation from Salinity Gradient Solar Pond Using Low-Grade Heat. Journal of Electronic Materials, 46, 2854-2859. https://doi.org/10.1007/s11664-016-5009-0

Singh, R., Tundee, S., \& Akbarzadeh, A. (2011). Electric power generation from solar pond using combined thermosyphon and thermoelectric modules. Solar Energy, 85(2), 371-378. https:// doi.org/10.1016/j.solener.2010.11.012

Sinha, A., Shahbaz, M., \& Balsalobre, D. (2017). Exploring the relationship between energy usage segregation and environmental degradation in N-11 countries. Journal of Cleaner Production, 168, 1217-1229. https://doi.org/10.1016/j.jclepro.2017.09.071

Skillicorn, D. (2007). Understanding complex datasets: Data mining with matrix decompositions. In Understanding Complex Datasets: Data Mining with Matrix Decompositions (1st Editio). https://doi.org/10.1201/9781584888338

Small, H., \& Garfield, E. (1985). The geography of science: Disciplinary and national mappings. Journal of Information Science, 11(4), 147-159. https://doi.org/10.1177/016555158501100402

Soltani, R., Mohammadzadeh Keleshtery, P., Vahdati, M., Khoshgoftarmanesh, M.H., Rosen, M.A., \& Amidpour, M. (2014). Multi-objective optimization of a solar-hybrid cogeneration cycle: Application to CGAM problem. Energy Conversion and Management, 81, 60-71. https://doi.org/10.1016/j.enconman.2014.02.013

Stolarski, M.J., Szczukowski, S., Tworkowski, J., Krzyzaniak, M., Gulczyński, P., \& Mleczek, M. (2013). Comparison of quality and production cost of briquettes made from agricultural and forest origin biomass. Renewable Energy, 57, 20-26. https://doi.org/10.1016/j.renene.2013. 01.005

【ัเง

Journal of Data and Information Science
Suarez, J.A., \& Luengo, C.A. (2003). Coffee Husk Briquettes: A New Renewable Energy Source. Energy Sources, 25(10), 961-967. https://doi.org/10.1080/00908310303395

Tarfaoui, M., Nachtane, M., \& Boudounit, H. (2019). Finite Element Analysis of Composite Offshore Wind Turbine Blades Under Operating Conditions. Journal of Thermal Science and Engineering Applications, 12(1), 011001. https://doi.org/10.1115/1.4042123

Tokimatsu, K., Konishi, S., Ishihara, K., Tezuka, T., Yasuoka, R., \& Nishio, M. (2016). Role of innovative technologies under the global zero emissions scenarios. Applied Energy, 162, 1483-1493. https://doi.org/10.1016/j.apenergy.2015.02.051 
Valderrama, C., Gibert, O., Arcal, J., Solano, P., Akbarzadeh, A., Larrotcha, E., \& Cortina, J.L. (2011). Solar energy storage by salinity gradient solar pond: Pilot plant construction and gradient control. Desalination, 279(1-3),445-450.https://doi.org/10.1016/j.desal.2011.06.035

Vazquez, M. de L., Waaub, J.P., \& Ilinca, A. (2013). MCDA: Measuring robustness as a tool to address strategic wind farms issues. Green Energy and Technology, 129, 153-182. https://doi. org/10.1007/978-1-4471-5143-2_8

Wang, J., Hu, J., Ma, K., \& Zhang, Y. (2015). A self-adaptive hybrid approach for wind speed forecasting. Renewable Energy, 78, 374-385. https://doi.org/10.1016/j.renene.2014.12.074

Wasserman, S., \& Faust, K. (1994). Social network analysis: Methods and applications. Cambridge University Press.

Whiteman, A., Sohn, H., Esparrago, J., Arkhipova, I., \& Elsayed, S. (2018). Renewable Capacity Statistics 2018. In /publications/2018/Mar/Renewable-Capacity-Statistics-2018. https:// www.irena.org/publications/2018/Mar/Renewable-Capacity-Statistics-2018

Wu, J. (2019). Infrastructure of Scientometrics: The Big and Network Picture. Journal of Data and Information Science, 4(4), 1-12. https://doi.org/10.2478/jdis-2019-0017

Wuestman, M.L., Hoekman, J., \& Frenken, K. (2019). The geography of scientific citations. Research Policy, 48(7), 1771-1780. https://doi.org/10.1016/j.respol.2019.04.004

Xu, H., Wang, C., Dong, K., Luo, R., Yue, Z., \& Pang, H. (2020). A study of methods to identify industry-university-research institution cooperation partners based on innovation Chain theory. Journal of Data and Information Science, 3(2), 38-61. https://doi.org/10.2478/jdis2018-0008

Yang, W., Wang, J., Lu, H., Niu, T., \& Du, P. (2019). Hybrid wind energy forecasting and analysis system based on divide and conquer scheme: A case study in China. Journal of Cleaner Production, 222, 942-959. https://doi.org/10.1016/j.jclepro.2019.03.036

Zhang, W., Kleiber, W., Florita, A.R., Hodge, B.M., \& Mather, B. (2019). Modeling and simulation of high-frequency solar irradiance. IEEE Journal of Photovoltaics, 9(1), 124-131. https://doi. org/10.1109/JPHOTOV.2018.2879756

Zhang, W., Maleki, A., Rosen, M.A., \& Liu, J. (2018). Optimization with a simulated annealing algorithm of a hybrid system for renewable energy including battery and hydrogen storage. Energy, 163, 191-207. https://doi.org/10.1016/j.energy.2018.08.112

\section{(c) $($ ()) $९$}

This is an open access article licensed under the Creative Commons Attribution-NonCommercialNoDerivs License (http://creativecommons.org/licenses/by-nc-nd/4.0/). 